\title{
On the Lathrobium fauna of China III. New species and additional records from various provinces (Coleoptera: Staphylinidae: Paederinae)
}

\author{
With 121 figures and 1 map \\ VOLKER ASSING ${ }^{1}$ \\ ${ }^{1}$ Gabelsberger Straße 2, 30163 Hannover, Germany. - vassing.hann@t-online.de \\ Published on 2013-06-14
}

\section{Summary}

Material of the paederine genus Lathrobium Gravenhorst, 1802 from the Chinese provinces Sichuan, Chongqing, Beijing, Zhejiang, Fujian, and Jiangxi is examined. Twenty-two species are identified, two of them described previously and nineteen undescribed. Sixteen species are described and illustrated: Lathrobium celere sp. n. (Sichuan: Gongga Shan); L. ventricosum sp. n. (Sichuan: Gongga Shan); L. bibaculatum sp. n. (Sichuan: Erlang Shan); L. bispinigerum sp. n. (Sichuan: Erlang Shan); L. bihastatum sp. n. (Sichuan: Daxiang Ling); L. aspinosum sp. n. (Sichuan: Erlang Shan); L. appendiculatum sp. n. (southern Sichuan); L. fortepunctatum sp. n. (Chongqing: Jinfo Shan); L. jinfoicum sp. n. (Chongqing: Jinfo Shan); L. imminutum sp. n. (Beijing: Dongling Shan); L. parvitergale sp. n. (Zhejiang: Tianmu Shan); L. barbiventre sp. n. (Fujian: Wuyi Shan); L. depravatum sp. n. (Jiangxi: Wuyi Shan: Huanggang Shan); L. cornigerum sp. n. (Jiangxi: Wuyi Shan: Huanggang Shan); L. wuyicum sp. n. (Jiangxi: Wuyi Shan: Huanggang Shan); L. pium sp. n. (Guizhou: Leigong Shan). Four undescribed species from Sichuan, Zhejiang, Jiangxi, and Guizhou remain unnamed, since they are represented exclusively by females. The phylogenetic affiliations of the examined species are discussed. The localities where the newly described species were collected are mapped. Including the newly described taxa, 111 described Lathrobium species are currently known from mainland China.

\section{Key words}

Coleoptera, Staphylinidae, Paederinae, Lathrobiina, Lathrobium, Palaearctic region, China, taxonomy, new species.

\section{New species}

Lathrobium celere sp. n., L. ventricosum sp.n., L. bibaculatum sp. n, L. bispinigerum sp. n., L. bihastatum sp. n., L. aspinosum sp. n., L. appendiculatum sp. n., L. fortepunctatum sp. n., L. jinfoicum sp. n., L. imminutum sp. n., L. parvitergale sp. n., L. barbiventre sp. n., L. depravatum sp. n., L. cornigerum sp. n., L. wuyicum sp. n., L. pium sp. n.

\section{Zusammenfassung}

Im Rahmen einer Untersuchung von Material der Gattung Lathrobium Gravenhorst, 1802 aus den chinesischen Provinzen Sichuan, Chongqing, Beijing, Zhejiang, Fujian, Jiangxi, und Guizhou wurden 21 Arten identifiziert, darunter 19 unbeschriebene Arten. Sechzehn Arten werden beschrieben und abgebildet: Lathrobium celere sp. n. (Sichuan: Gongga Shan); L. ventricosum sp. n. (Sichuan: Gongga Shan); L. bibaculatum sp. n. (Sichuan: Erlang Shan); L. bispinigerum sp. n. (Sichuan: Erlang Shan); L. bihastatum sp. n. (Sichuan: Daxiang Ling); L. aspinosum sp. n. (Sichuan: Erlang Shan); L. appendiculatum sp. n. (southern Sichuan); L. fortepunctatum sp. n. (Chongqing: 
Jinfo Shan); L. jinfoicum sp. n. (Chongqing: Jinfo Shan); L. imminutum sp. n. (Beijing: Dongling Shan); L. parvitergale sp. n. (Zhejiang: Tianmu Shan); L. barbiventre sp. n. (Fujian: Wuyi Shan); L. depravatum sp. n. (Jiangxi: Wuyi Shan: Huanggang Shan); L. cornigerum sp. n. (Jiangxi: Wuyi Shan: Huanggang Shan); L. wuyicum sp. n. (Jiangxi: Wuyi Shan: Huanggang Shan); L. pium sp. n. (Guizhou: Leigong Shan). Vier unbeschriebene Arten aus Sichuan, Zhejiang, Jiangxi und Guizhou wurden nicht benannt, da sie nur durch Weibchen vertreten waren. Die phylogenetischen Beziehungen der behandelten Arten werden diskutiert. Die Lage der Fundorte der neu beschriebenen Arten wird anhand einer Karte illustriert. Einschließlich der neuen Arten ist Lathrobium auf dem chinesischen Festland mit derzeit 111 beschriebenen Arten vertreten.

\section{Introduction}

In the Palaearctic region, the speciose paederine genus Lathrobium GravenHorst, 1802 is represented by more than 400 described species, 95 of which have been reported from mainland China (Assing in press, AssING et al. 2013). With few exceptions, these species are micropterous and have restricted distributions. Thus, Lathrobium is represented in mainland China by considerably more endemic species than any other genus of the Paederinae. The Chinese provinces with the greatest diversity (doubtful records not included) are Shaanxi (20 described species), Yunnan (18 described species), Sichuan (18 species), Zhejiang (16 species), Gansu (7 species), and Guangxi (7 species). These figures, however, are probably strongly biased. The Lathrobium fauna of Shaanxi and of Zhejiang has been studied more comprehensively (Assing in press) or more frequently (PENG et al. 2012a, d, e; WATANABE 1999a, b), respectively, than that of most other provinces. Moreover, previous studies suggest that, except for northern China, all the mountain ranges host several endemic species. The Emei Shan, for instance, is inhabited by at least six endemic species (Assing et al. 2013). However, the Lathrobium fauna of numerous mountain ranges has not been examined, suggesting that the true diversity of the genus in China is far greater than currently known. Finally, preliminary studies of collection material have shown that the number of undescribed species, particularly in Yunnan, is enormous.

After two studies focusing on the Lathrobium species of the Qinling Shan, the Daba Shan, and adjacent mountain ranges (Assing in press), as well as of the Emei Shan in Sichuan (Assing et al. 2013), the present paper represents the third contribution to the Lathrobium fauna of mainland China and addresses species from various provinces: Sichuan, Chongqing, Beijing, Zhejiang, Fujian, Jiangxi, and Guizhou. Previously, two species were known from Chongqing, one (widespread) from Beijing, two from Fujian, one from Guizhou, and none from Jiangxi. The diverse fauna of Yunnan will be treated separately.

This study is mainly based on material made available to me by Michael Schülke (Berlin), Aleš Smetana (Ottawa), Peter Hlaváč (Praha), and Andreas Pütz (Eisenhüttenstadt).

\section{Material, methods, and measurements}

The material referred to in this study is deposited in the following public institutions and private collections:

$\begin{array}{ll}\text { NHMW } & \begin{array}{l}\text { Naturhistorisches Museum Wien (H. Schill- } \\ \text { hammer) }\end{array} \\ \text { SNUC } & \begin{array}{l}\text { Insect Collection of Shanghai Normal Univer- } \\ \text { sity, Shanghai }\end{array} \\ \text { cAss } & \begin{array}{l}\text { author's private collection } \\ \text { private collection Andreas Pütz, Eisenhütten- } \\ \text { cPüt }\end{array} \\ \text { stadt } \\ \text { cSch } & \begin{array}{l}\text { private collection Michael Schülke, Berlin } \\ \text { private collection Aleš Smetana, Ottawa }\end{array}\end{array}$

The morphological studies were conducted using a Stemi SV 11 microscope (Zeiss Germany) and a Jenalab compound microscope (Carl Zeiss Jena). A digital camera (Nikon Coolpix 995) was used for the photographs. The map was created using MapCreator 2.0 (primap) software.

Body length was measured from the anterior margin of the mandibles (in resting position) to the abdominal apex, the length of the forebody from the anterior margin of the mandibles to the posterior margin of the elytra, head length from the anterior margin of the frons to the posterior margin of the head, elytral length at the suture from the apex of the scutellum to the posterior margin of the elytra (at the suture), and the length of the aedeagus from the apex of the ventral process to the base of the aedeagal capsule. The "parameral" side (i.e., the side where the sperm duct enters) is referred to as the ventral, the opposite side as the dorsal aspect.

\section{Results}

The examined material is composed of twenty-one species, two of them described previously and the remainder undescribed. Sixteen species are newly described; the remaining four undescribed species remain unnamed, since they are represented exclusively by females. Seven of the newly described species are from Sichuan, two from Chongqing, one from Beijing, one from Zhejiang, one from Fujian, three from Jiangxi, and one from Guizhou. The geographic positions of the mountain ranges where the new species were collected are illustrated in Map 1. 


\section{Species from Sichuan}

The Lathrobium fauna of Sichuan previously comprised eighteen described species. The true diversity, however, is most likely vastly greater. As many as seven species are described below, mostly from the Gongga Shan (two species) and the Erlang Shan (three species). Considering that the Emei Shan alone hosts at least six endemic species, the Erlang Shan at least four species, and the Gongga Shan at least three species, and that, so far, only the Lathrobium faunas of these mountain ranges and of some regions in northern Sichuan have been studied more thoroughly, numerous additional species can be expected to occur in the other mountainous regions that have not yet been investigated.

While the Lathrobium fauna of both the Emei Shan and of the Erlang Shan is composed of two phylogenetic lineages, the three species known from the Gongga Shan represent three different species groups.

Five species from the Erlang Shan, the Daxiang Ling, and the Labahe Natural Reserve form a distinct species group hereafter referred to as the L. bibaculatum group and including L. bibaculatum, L. bispinigerum, L. bihastatum, L. labahense PENG et al. 2012, and an undescribed species from the Erlangshan (L. erlangense PENG \& LI, in litt.). The monophyly of this group is supported by the synapomorphic presence of a pair of elongated sclerotized spines in the internal sac of the aedeagus. Within this group, L. bibaculatum + L. bispinigerum and L. bihastatum + L. erlangense represent species pairs, as is suggested particularly by the similar morphology of the aedeagus.

\section{Lathrobium hailuogouense PENG, LI \& ZHAO, 2012}

\section{Material examined:}

China: Sichuan: $8 \sigma^{-1} \sigma^{*}, 7$ 우, Gongga Shan, Hailuogou,

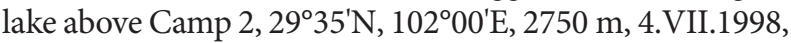
leg. Smetana (cSme, cAss); 3 우 ㅇ, Gongga Shan, Hailuogou, forest above Camp 2, $29^{\circ} 35^{\prime} \mathrm{N}, 102^{\circ} 00^{\prime} \mathrm{E}, 2800 \mathrm{~m}$, 5.VII.1998, leg. Smetana (cSme, cAss); $50^{\star} \sigma^{*}, 3$ 우 우 Gongga Shan, Hailuogou, lake above Camp 2, $2750 \mathrm{~m}$, 25.VII.1994, leg. Smetana (cSme, cAss); $10^{*}, 3$ 우 ㅇ, same data, but 24.VII.1994 (cSme, cAss); 1 o , 3 우 우, same data, but 27.VII.1994 (cSme, cAss); 1 ㅇ, same data, but $2850 \mathrm{~m}$, 26.VII.1994 (cSme); 1 o $^{\star}$, Gongga Shan, Hailuogou Glacier Park, Camp 2 env., 2650 m, 30.V.1997, leg. Pütz (cPüt); $30^{\star} o^{\star}, 3$ 우 웅, Gongga Shan, Hailuogou Glacier Park, Camp 1, 293' $\mathrm{N}, 102^{\circ} 04^{\prime} \mathrm{E}, 2100 \mathrm{~m}, 27 .-31 . V .1997$, leg. Schülke \& Wrase (cSch, cAss); $10^{\star}, 2$ ㅇ ㅇ, Gongga Shan, Hailuogou Glacier Park, Camp 2 env., $29^{\circ} 35^{\prime} \mathrm{N}, 102^{\circ} 02^{\prime} \mathrm{E}$, 2500-2700 m, 30-31.V.1997, leg. Schülke \& Wrase (cSch, cAss); $1 \sigma^{\star}$, Gongga Shan, Hailuogou Glacier Park, river valley ca. $1 \mathrm{~km}$ above Camp 1,293' $\mathrm{N}, 102^{\circ} 04^{\prime} \mathrm{E}, 2100 \mathrm{~m}$, 28.\&31.V.1997, leg. Pütz (cAss).

\section{Comment:}

The original description of Lathrobium hailuogouense is based on 23 type specimens from Hailuogou, Gongga Shan $\left(29^{\circ} 41^{\prime} \mathrm{N}, 102^{\circ} 06^{\prime} \mathrm{E}\right)$, collected at altitudes of 2200 $3000 \mathrm{~m}$ (PEng et al. 2012b). The above specimens were found close to the localities where the types were collected. The external and sexual characters of L. hailuogouense do not suggest a closer phylogenetic relationship to either of the two following species from the Gongga Shan.

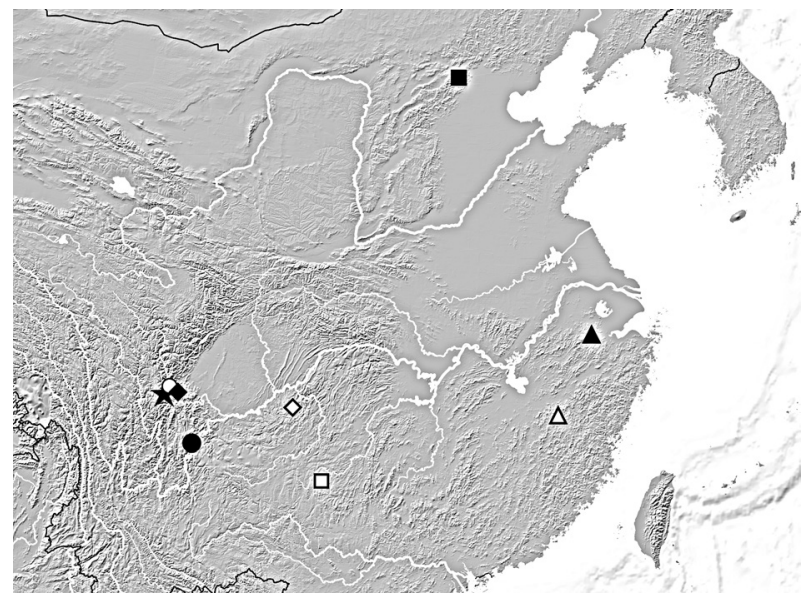

Map 1: Geographic position of the mountain ranges where the newly described species were collected. Filled star: Gongga Shan (Sichuan); open circle: Erlang Shan (Sichuan); filled diamond: Daxiang Ling (Sichuan); filled circle: type locality of L. appendiculatum (southern Sichuan); open diamond: Jinfo Shan (Chongqing); filled square: Dongling Shan (Beijing); filled triangle: Tianmushan (Zhejiang); open triangle: Wuyi Shan: Huanggang Shan (Jiangxi, Fujian); open square: Leigong Shan (Guizhou).

\section{Lathrobium celere sp. $\mathrm{n}$.}

(Figs 1-10)

\section{Type material:}

Holotype ơ: "CHINA: W-Sichuan (15), Daxue Shan, Hailuogou Glacier Park, Camp 2, 2550-2700 m, 29.35.16N, 102.01.53E, 30.-31.V.1997, M. Schülke / Holotypus o Lathrobium celere sp. n., det. V. Assing 2012" (cAss). Paratypes: $1 \sigma^{\star}$ : "China: Sichuan, Daxue Shan, Gongga Shan Mt., Hailougou [sic] Glacier Park, 102.04E, $29.36 \mathrm{~N}$, river valley ca. $1 \mathrm{~km}$ above Camp 1, $2100 \mathrm{~m}$, 28.\&31.V.1997, leg. A. Pütz" (cAss); 1 ㅇ: "CHINA: Sichuan, Gongga Shan, Hailuogou, for. above Camp 2, $2800 \mathrm{~m}, 29^{\circ} 35 \mathrm{~N}, 102^{\circ} 00 \mathrm{E}, 5 . \mathrm{VII} .1998$, A. Smetana [C75] / 1998 China Expedition, J. Farkač, D. Král, J. Schneider \& A. Smetana" (cSme).

\section{Etymology:}

The specific epithet (Latin, adjective: quick, hurried) alludes to the long legs. 


\section{Description:}

Species of conspicuously slender habitus (Fig. 1) and of moderate to moderately large size, with pronounced sexual size dimorphism. Body length 9.5-10.0 mm ( $\left.\sigma^{\star}\right)$, $7.8 \mathrm{~mm}$ ( क ) ; length of forebody $4.3 \mathrm{~mm}\left(0^{+}\right), 3.85 \mathrm{~mm}$ ( 9 ). Coloration: body dark-brown to blackish-brown, elytra partly more or less extensively paler brown; legs reddish to pale reddish-brown; antennae reddish.

Head (Fig. 2) distinctly oblong, 1.10-1.12 times as long as broad; punctation coarse and moderately dense, sparser in median dorsal portion; interstices silk mat, with fine but very distinct microreticulation. Eyes weakly convex and relatively large, more than one third the length of postocular region in dorsal view and composed of approximately 50 ommatidia. Antenna approximately 2.4 $\left(o^{\top}\right)$ and $2.0 \mathrm{~mm}$ ( + ) long, respectively.

Pronotum (Fig. 2) slender, 1.25-1.30 times as long as broad and about 1.02 times as broad as head; punctation slightly finer and less dense than that of head; impunctate midline moderately broad; interstices without microsculpture.

Elytra (Fig. 2) short, approximately 0.55 times as long as pronotum; punctation fine, sparse, shallow, and often weakly defined. Hind wings completely reduced. Legs slender, metatibia nearly as long as pronotum. Protarsi

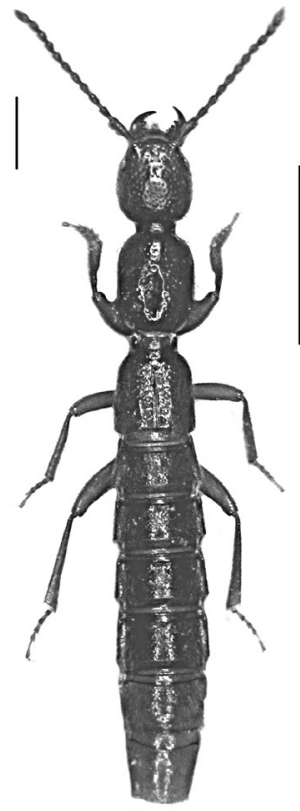

1

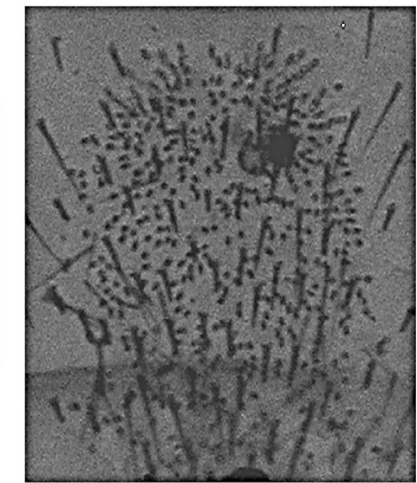

5

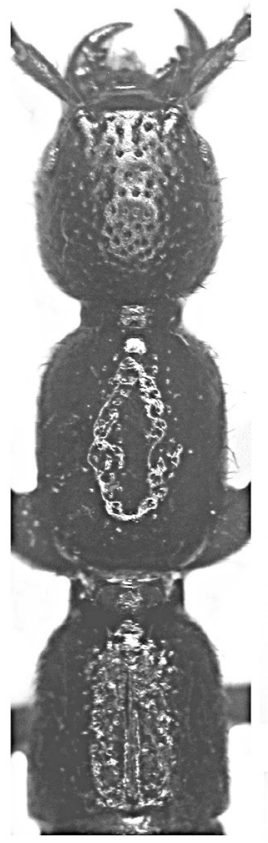

2

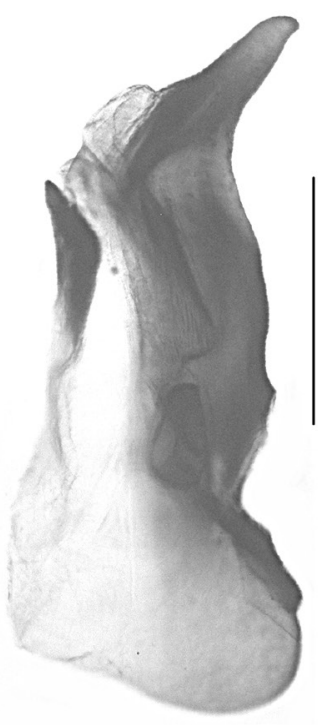

6

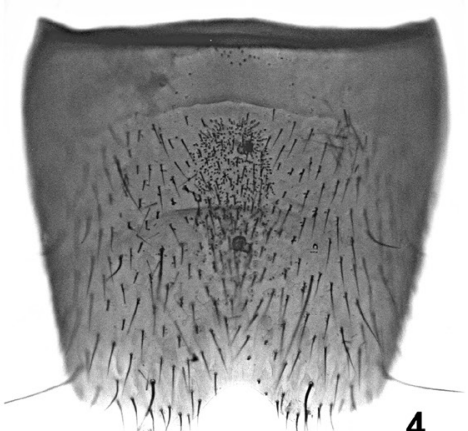

4

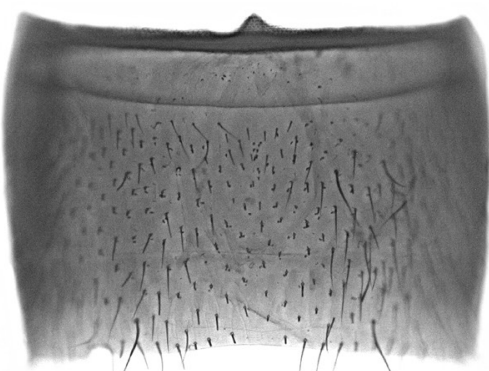

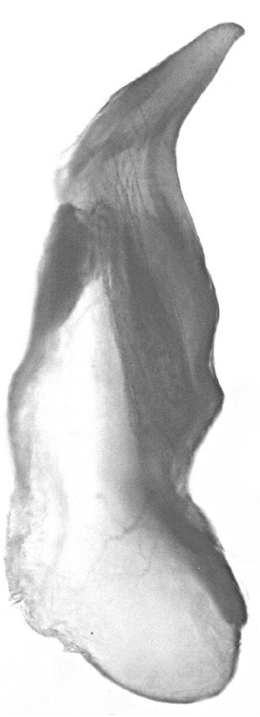

7

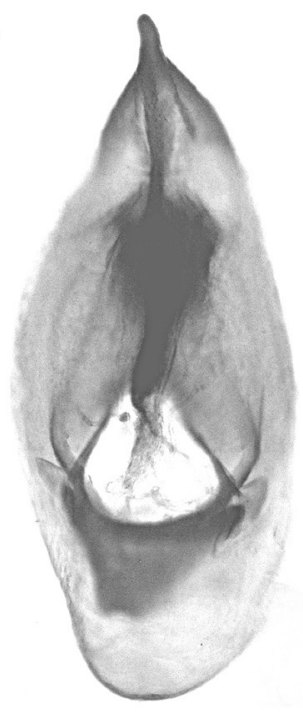

8
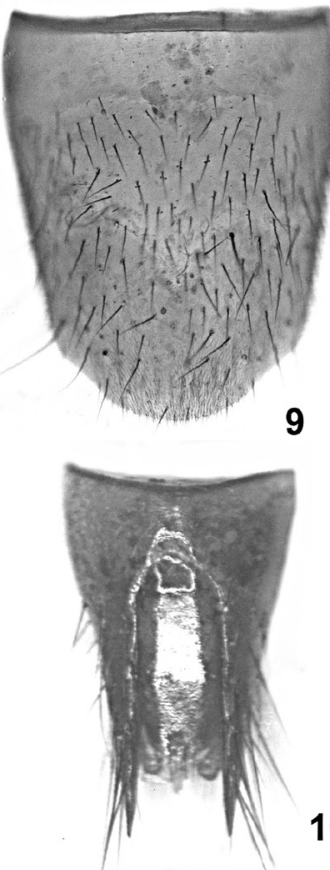

Figs 1-10: Lathrobium celere sp. n.: habitus (1); forebody (2); male sternite VII (3); male sternite VIII (4); median portion of male sternite VIII (5); aedeagus in lateral and in ventral view (6-8); female sternite VIII (9); female tergites IX-X (10). Scale bars: 1-2: $1.0 \mathrm{~mm}$; 3-4, 6-10: $0.5 \mathrm{~mm}$; 5: $0.2 \mathrm{~mm}$. 
without appreciable sexual dimorphism, moderately dilated in both sexes.

Abdomen with moderately fine and moderately dense punctation, that of tergite VII noticeably sparser than that of anterior tergites; interstices with fine and shallow microsculpture, somewhat glossy; posterior margin of tergite VII without palisade fringe; tergite VIII without sexual dimorphism, posterior margin indistinctly pointed in the middle in both sexes.

$0^{\star}$ : sternites III-VI unmodified; sternite VII moderately transverse, with unmodified pubescence, and with broadly and weakly concave posterior margin (Fig. 3); sternite VIII (Fig. 4) approximately as long as broad, symmetric, pubescence unmodified except for the somewhat shorter setae in anterior median portion, posterior excision small and of almost semi-circular shape, median portion of sternite with cluster of (gland?) pores (Fig. 5); aedeagus (Figs 6-8) 1.3-1.4 mm long, compact, with short, stout, and apically acute ventral process; dorsal plate small, with strongly sclerotized apical and weakly sclerotized basal portion; internal sac without sclerotized structures.

क: sternite VIII $1.1 \mathrm{~mm}$ long, distinctly oblong, and with strongly convex posterior margin (Fig. 9); tergite IX with very short and undivided median portion and with long postero-lateral processes; tergite X flat and approximately 4 times as long as tergite IX in the middle (Fig. 10).

\section{Comparative notes:}

This highly distinctive species differs from all other geographically close congeners by numerous external characters alone: the pronounced sexual size dimorphism, the slender habitus and long legs, the distinctly oblong and silk-matt head, and the absence of a sexual dimorphism of the protarsi. In addition, it is characterized by conspicuous sexual characters, particularly the shape and chaetotaxy of the male sternite VIII, the morphology of the aedeagus (shape of ventral process and of dorsal plate), as well as by the morphology of the female tergites IX and X. The presence of a cluster of pores, most likely gland openings, in the median portion of the male sternite VIII appears to be unique among East Palaearctic Lathrobium species. Shared derived characters suggesting closer phylogenetic affiliations with other described species recorded from China were not found.

\section{Distribution and natural history:}

Lathrobium celere is probably endemic to the Gongga Shan, where it was collected in three localities at altitudes of 2100-2800 m. Remarkably, only singletons were collected in these localities, which, together with the slender habitus and the long appendages, suggests that the species lives in a special, cryptic habitat and not in the leaf litter layer.

\section{Lathrobium ventricosum sp. $\mathrm{n}$.}

(Figs 11-18)

\section{Type material:}

Holotype ơ: "CHINA Sichuan, Gongga Shan, Hailuogou, above Camp 3, 3050 m 6.VII.96, 29³5N, 102 ${ }^{\circ} 00 \mathrm{E}, \mathrm{C} 52 /$ collected by A. Smetana, J. Farkač and P. Kabátek / Holotypus o Lathrobium ventricosum sp. n., det. V. Assing 2012" (cSme). Paratypes: 7 o $^{\star} 0^{\star}, 6$ ㅇ o : same data as holotype (cSme, cAss, cSch); 1 ㅇ: "CHINA Sichuan, Gongga Shan, Hailuogou, above Camp 3, $3200 \mathrm{~m}$ 7.VII.96, $29^{\circ} 35 \mathrm{~N}, 102^{\circ} 00 \mathrm{E}, \mathrm{C} 54$ / collected by A. Smetana, J. Farkač and P. Kabátek" (cSme); $20^{\star} \sigma^{\star}, 1$ \%: "CHINA Sichuan, Gongga Shan, Hailuogou, above Camp 3, $3100 \mathrm{~m}$ 8.VII.96, $29^{\circ} 35 \mathrm{~N}, 102^{\circ} 00 \mathrm{E}, \mathrm{C} 56 /$ collected by A. Smetana, J. Farkač and P. Kabátek" (cSme, cAss); $60^{\star} 0^{\star}, 3$ ㅇ 우: "CHINA, Sichuan, Gongga Shan, above Camp 3, 3050 m, 22.VII.1994, A. Smetana [C18]" (cSme, cAss); 5 o $^{\star} o^{*}$, 4 ㅇ 우: "CHINA, Sichuan, Gongga Shan, abv. Camp 3, 3300-3350 m, 23.VII.1994, A. Smetana [C19]" (cSme, cAss); $4 o^{\star} o^{\star}$ : “CHINA: Sichuan Gongga Shan, Hailuogou, Lake above Camp 2, $2750 \mathrm{~m}, 29^{\circ} 35 \mathrm{~N}, 102^{\circ} 00 \mathrm{E}$, 4.VII.1998, A. Smetana [C74] / 1998 China Expedition, J. Farkač, D. Král, J. Schneider \& A. Smetana" (cSme, cAss); 1 : "CHINA: Sichuan Gongga Shan, Hailuogou, in front of Glacier 1, $2850 \mathrm{~m}, 29^{\circ} 35 \mathrm{~N}, 102^{\circ} 00 \mathrm{E}$, 7.VII.1998, A. Smetana [C75] / 1998 China Expedition, J. Farkač, D. Král, J. Schneider \& A. Smetana” (cSme).

\section{Etymology:}

The specific epithet (Latin, adjective: fat, adipose) alludes to the short and large abdomen.

\section{Description:}

Species of short and stout habitus (Fig. 11) and of relatively small size, with moderate sexual size dimorphism. Body length 5.8-7.0 mm ( $\left.\sigma^{*}\right), 5.2-6.2 \mathrm{~mm}$ (क); length of forebody 2.9-3.3 mm ( $\left.o^{\star}\right), 2.7-3.0 \mathrm{~mm}$ ( ( + ). Coloration: body dark reddish-brown to blackish-brown; legs reddish to reddish-brown; antennae reddish.

Head (Fig. 12) approximately 1.05 times as long as broad, distinctly dilated posteriorly; punctation moderately coarse and rather sparse, even slightly sparser in median dorsal portion; interstices glossy, with very shallow, partly almost obsolete microreticulation. Eyes weakly convex and relatively large, approximately one third the length of postocular region in dorsal view and composed of approximately 40-50 ommatidia. Antenna 1.5-1.7 mm long.

Pronotum (Fig. 12) rather short, approximately 1.2 times as long as broad and about 1.05-1.10 times as broad as head; punctation similar to that of head, but slightly denser; impunctate midline moderately broad; interstices without microsculpture. 
Elytra (Fig. 12) short, 0.52-0.55 times as long as pronotum; punctation somewhat variable, usually moderately dense, shallow, and weakly defined. Hind wings completely reduced. Protarsi with moderately pronounced sexual dimorphism.

Abdomen large and short, distinctly dilated from segments III to VI, widest at segments V/VI, approximately 1.15 times as broad as elytra; punctation fine and moderately dense, only slightly sparser on tergite VII than on anterior tergites; microsculpture fine and shallow, interstices rather glossy; posterior margin of tergite VII without palisade fringe; tergite VIII without sexual dimorphism, posterior margin weakly convex in both sexes.

$0^{\star}$ : protarsomeres I-IV strongly dilated; sternites III-VI unmodified; sternite VII (Fig. 13) transverse, approximately twice as broad as long, with extensive median impression, this impression with numerous moderately modified, short dark setae on either side of middle, posterior margin broadly and weakly concave, more distinctly concave in the middle; sternite VIII (Fig. 14) distinctly transverse and with shallowly concave posterior excision, pubescence unmodified; aedeagus (Figs 15-16) 1.4-1.5 mm long, symmetric; ventral process straight, not distinctly separated from aedeagal capsule; dorsal plate short, weakly sclerotized, and apically with acute and slender process; internal sac without sclerotized structures.

i : protarsomeres I-VI distinctly dilated, but less so than in male; sternite VIII (Fig. 17) approximately $1.0 \mathrm{~mm}$ long, approximately as long as broad; middle of posterior margin more or less truncate; tergite IX completely separated in the middle and with short postero-lateral processes; tergite $\mathrm{X}$ flat, reaching anterior margin of tergite IX (Fig. 18).

\section{Comparative notes:}

This highly distinctive species differs from all other geographically close congeners by numerous external and sexual characters, particularly the habitus with a relatively short and stout abdomen, the moderately pronounced sexual size dimorphism, the shallow microsculpture of the head, the shape and chaetotaxy of the male sternites

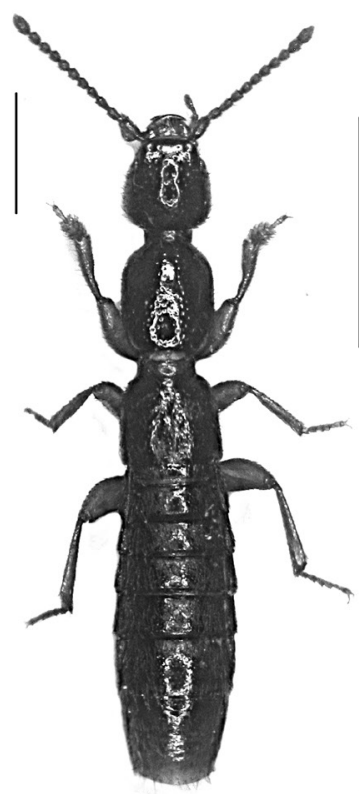

11

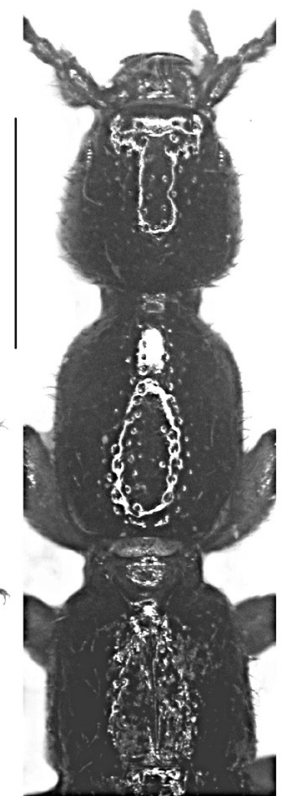

12

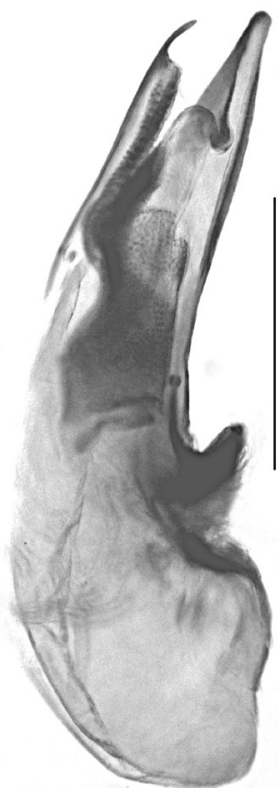

15

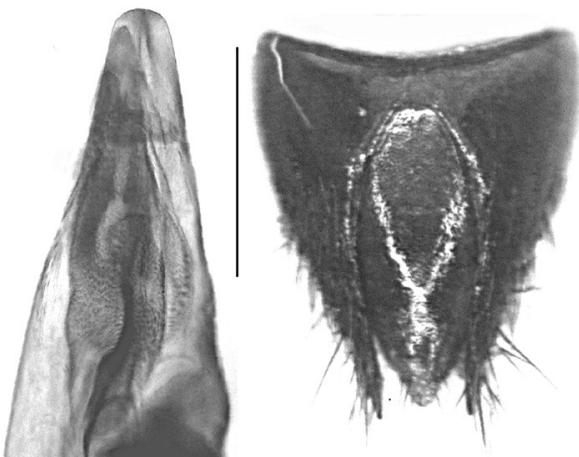

18

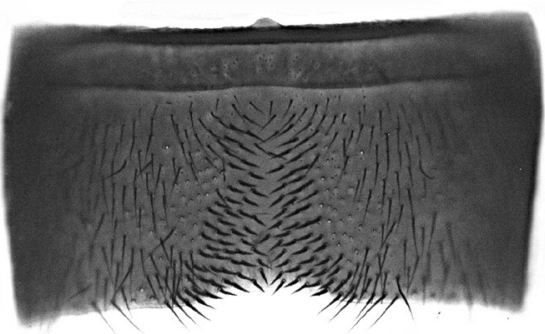

13

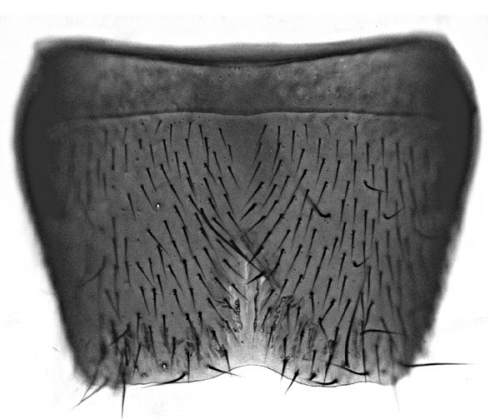

14

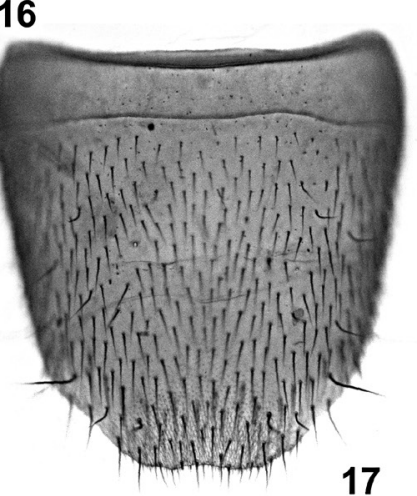

Figs 11-18: Lathrobium ventricosum sp. n.: habitus (11); forebody (12); male sternite VII (13); male sternite VIII (14); aedeagus in lateral and in ventral view (15-16); female sternite VIII (17); female tergites IX-X (18). Scale bars: 11-12: 1.0 mm; 13-18: 0.5 mm. 
VII and VIII (especially the strongly transverse male sternite VII), the morphology of the aedeagus (ventral process fused with aedeagal capsule; dorsal plate of distinctive shape), and the female terminalia (short sternite VIII; completely divided tergite IX). Shared derived characters suggesting closer phylogenetic affiliations with other described species recorded from China were not found.

\section{Distribution and natural history:}

Lathrobium ventricosum is most likely endemic to the Gongga Shan, where it is apparently confined to higher elevations. The specimens were sifted in several localities at altitudes of 2750-3350 m.

\section{Lathrobium bibaculatum sp. n.}

(Figs 19-25, 32)

\section{Type material:}

Holotype ơ: "CHINA: W-Sichuan 1999, Ya’an Prefecture, Tianquan Co., E Erlang Shan Pass, 2900 m, 9 km SE Luding, $29^{\circ} 52 \mathrm{~N}, 102^{\circ} 18 \mathrm{E}$, Gesiebe, 20.VI., leg. M. Schülke / Holotypus o Lathrobium bibaculatum sp. n., det. V. Assing 2012” (cAss). Paratypes: 4 ơ ơ, 3 ㅇ 우 : “CHINA W. Sichuan (Ganzi Tibet. Aut. Pref., Luding Co.) Erlang Shan Pass, Road 318, ca. 3000 m, 8 km SE Luding, 190 km SW Chengdu, 21.-29.VI.1999, D. W. Wrase" (cSch, cAss); 1 o", 1 \%: "CHINA: W-Sichuan 1999, Ganzi Tibet. Aut. Pref., Luding Co., W Erlang Shan Pass, 2900 m, $29^{\circ} 51 \mathrm{~N}, 102^{\circ} 17 \mathrm{E}$, Weiden + Moos, Blockhalde, 21.VI., leg. M. Schülke" (cSch, cAss); 1 ㅇ: "CHINA: W-Sichuan 1999, Yaan Prefecture, Tianquan Co., E Erlang Shan Pass, $2900 \mathrm{~m}, 9 \mathrm{~km}$ SE Luding, $29^{\circ} 52 \mathrm{~N}, 102^{\circ} 18 \mathrm{E}$,

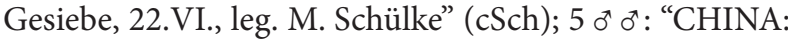
W-Sichuan, Yaan Prefecture, Tianquan Co., W Erlang Shan Pass / 2900 m, 21.VI.1999, 29.51.13N, 102.17.28E, leg. A. Pütz, sifted" (cPüt, cAss); $10^{*}$ : same data, but 29.VI.1999" (cPüt); 1 क : “CHINA: W-Sichuan, Ya’an Prefecture, Tianquan Co., W Erlang Shan Pass, 2780 m, 29.VI.1999, 29.51.27N, 102.15.47E, leg. A. Pütz, sifted" (cPüt); $2 \sigma^{\star} \sigma^{\prime}, 1$ ㅇ: "CHINA: Sichuan Prov., Tianquan County, Mt. Erlangshan, $29^{\circ} 52^{\prime} \mathrm{N}, 102^{\circ} 17^{\prime} \mathrm{E} / 11$.vii.2012, alt. 2,600-2,800 m, Dai, Peng \& Yin leg." (SNUC).

\section{Etymology:}

The specific epithet (Latin, adjective: with two sticks) alludes to the presence of two long spines in the internal sac of the aedeagus.

\section{Description:}

Relatively small species, without evident sexual size dimorphism. Body length 6.5-7.5 mm; length of forebody 2.9-3.3 mm. Coloration: body dark-brown to blackishbrown, elytra sometimes slightly paler brown; legs reddish to pale reddish-brown; antennae reddish.
Head (Fig. 19) approximately as long as broad; punctation moderately coarse and moderately dense, sparser in median dorsal portion; interstices with pronounced microreticulation, nearly matt. Eyes weakly convex and moderately small, one fourth to nearly one third the length of postocular region in dorsal view and composed of approximately 40-50 ommatidia. Antenna 1.7-1.8 mm long.

Pronotum (Fig. 19) slender, 1.26-1.30 times as long as broad and 1.20-1.05 times as broad as head; punctation similar to that of head; impunctate midline rather narrow to moderately broad; interstices without microsculpture.

Elytra (Fig. 19) short, approximately 0.55 times as long as pronotum; punctation fine, sparse, shallow, and often weakly defined. Hind wings completely reduced. Protarsi with pronounced sexual dimorphism.

Abdomen with very fine, somewhat indistinct, and not particularly dense punctation, that of tergite VII distinctly sparser than that of anterior tergites; interstices with fine microsculpture; posterior margin of tergite VII without palisade fringe; tergite VIII without sexual dimorphism, posterior margin weakly convex to indistinctly obtusely pointed in the middle.

$\sigma^{*}$ : protarsomeres I-IV strongly dilated; sternites III-VI unmodified; sternite VII (Fig. 20) moderately transverse, symmetric, and with shallow median impression of triangular shape posteriorly, this impression with rather sparse strongly modified, short and stout black setae, posterior margin weakly concave in the middle; sternite VIII (Fig. 21) weakly transverse, symmetric, and with long median impression, this impression with unmodified setae, posterior margin weakly and broadly concave; aedeagus (Figs 22-24) 1.0-1.1 mm long, symmetric, and with slender ventral process, apical portion of dorsal plate thin, lamellate, and rather weakly sclerotized, basal portion of dorsal plate short and extremely thin, internal sac with pair of distinctly sclerotized, very long spines.

ㅇ: protarsomeres I-IV moderately dilated, much less so than in male; sternite VIII (Fig. 32) approximately $0.9 \mathrm{~mm}$ long, weakly oblong, and with strongly convex posterior margin; tergite IX with median portion undivided and short, posterior processes moderately long and slender; tergite $\mathrm{X}$ flat and more than twice as long as tergite IX in the middle (Fig. 25).

\section{Comparative notes:}

Based on the similar external and sexual characters, particularly the presence of a pair of spines in the internal sac and the shape of the ventral process of the aedeagus, L. bibaculatum is the sister species of L. bispinigerum, an endemic of the same mountain. For distinguishing characters see the comparative notes in the following section. 
Distribution and natural history:

The species is probably endemic to the Erlang Shan in western Sichuan. The specimens were sifted from leaf litter and moss at elevations between approximately 2700 and $3000 \mathrm{~m}$.
Lathrobium bispinigerum sp. $\mathrm{n}$.

(Figs 26-31, 33-35)

\section{Type material:}

Holotype ơ: "CHINA: W-Sichuan 1999, Ganzi Tibet. Aut. Pref., Luding Co., W Erlangshan-Pass, $2600 \mathrm{~m}$, $7 \mathrm{~km}$ SSE Luding, $29^{\circ} 51^{\prime} \mathrm{N}, 102^{\circ} 15^{\prime} \mathrm{E}$, Laubstreu, Pilze, 29.VI., leg. M. Schülke / Holotypus ơ Lathrobium bispinigerum sp. n., det. V. Assing 2012" (cSch). Paratypes: $40^{\top} o^{\top}, 6$ 우 ㅇ: same data as holotype (cSch, cAss); $10^{\star *}$ : "CHINA: W-Sichuan 1999, Yáan Prefecture, Tianquan Co., E Erlangshan Pass, 2900 m, 9 km SE Luding, 2952N,

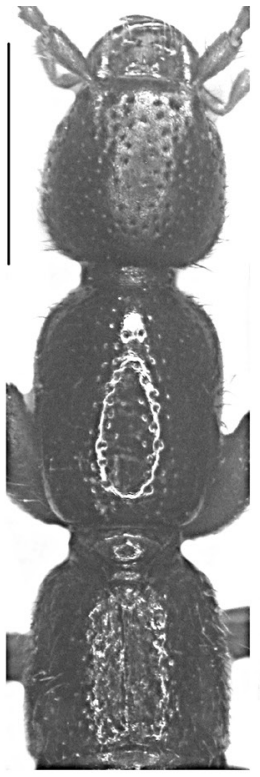

19

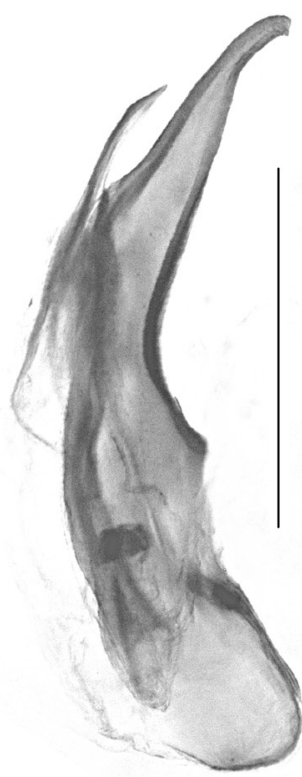

22

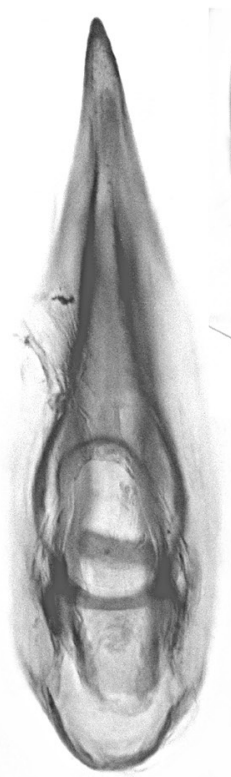

23

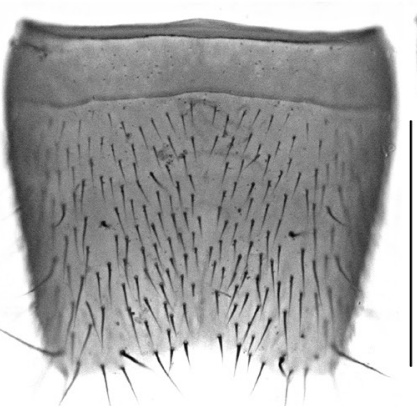

21

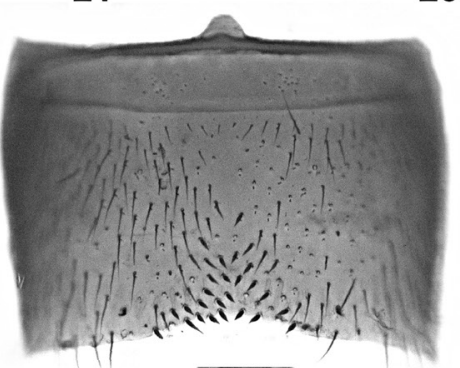

20

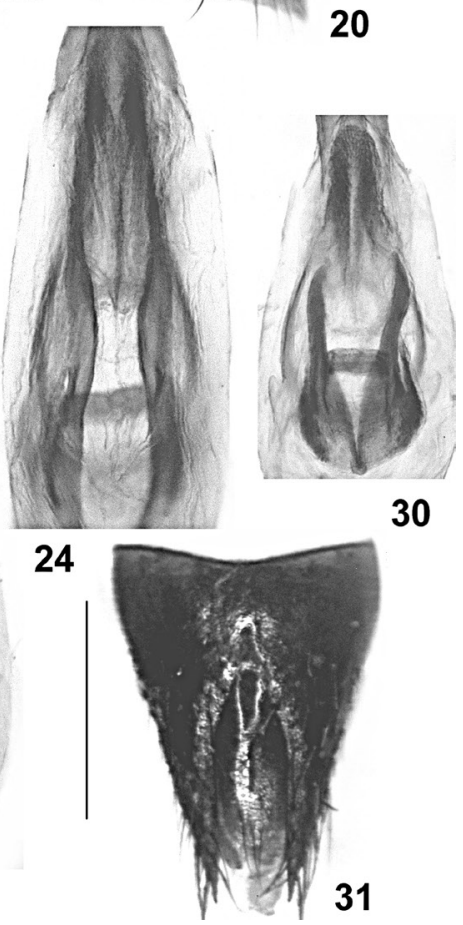

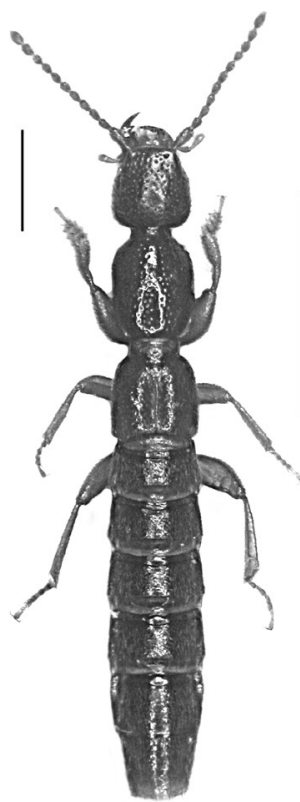

26

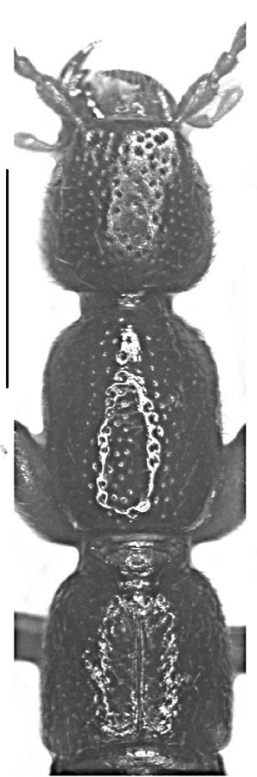

27

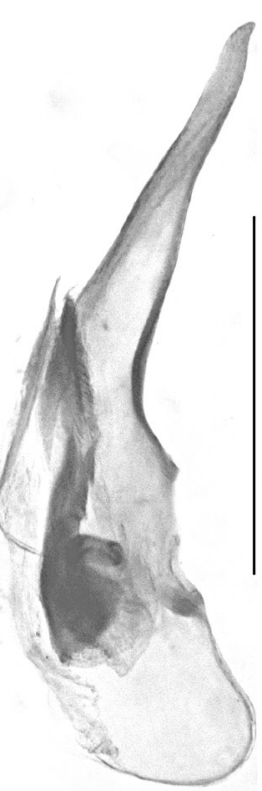

28

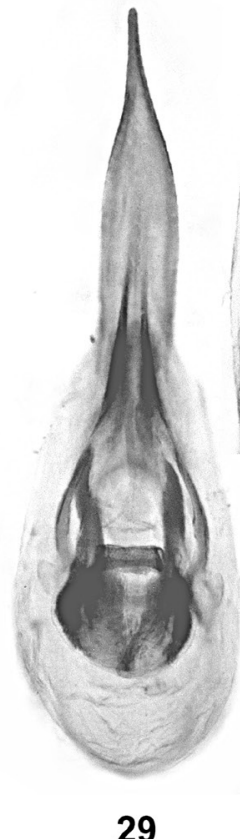

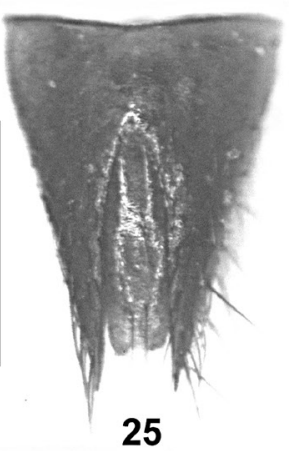

5

Figs 19-31: Lathrobium bibaculatum sp. n. (19-25) and L. bispinigerum sp. n. (26-31): forebody (19, 27); male sternite VII (20); male sternite VIII (21); aedeagus in lateral and in ventral view (22-23, 28-29); internal structures of aedeagus in dorsal view $(24,30)$; female tergites IX-X (25, 31); habitus (26). Scale bars: 19, 26-27: $1.0 \mathrm{~mm}$; 20-25, 28-31: $0.5 \mathrm{~mm}$. 
$102^{\circ} 18 \mathrm{E}$, Gesiebe, 20.VI., leg. M. Schülke” (cAss); 1 ㅇ : "CHINA: W-Sichuan, Ya'an Prefecture, Tianquan Co., W Erlang Shan Pass / 2780 m, 21.VI.1999, 29.51.27N,

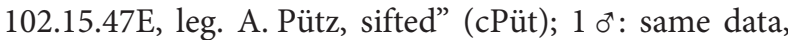
but 29.VI.1999 (cAss)

\section{Etymology:}

The specific epithet (Latin, adjective: with two spines) refers to the presence of two sclerotized spines in the internal sac of the aedeagus.

\section{Description:}

Relatively small species, without evident sexual size dimorphism. Body length 6.2-7.0 mm; length of forebody 2.7-3.1 mm. Habitus as in Fig. 26. Coloration: body darkbrown to blackish-brown, elytra often more or less extensively paler brown; legs reddish to pale reddish-brown; antennae reddish.

Head (Fig. 27) as long as broad or weakly transverse, 1.00-1.04 times as broad as long; punctation moderately coarse and moderately dense, sparser in median dorsal portion; interstices with distinct microreticulation. Eyes weakly convex and moderately small, one fourth to nearly one third the length of postocular region in dorsal view and composed of approximately 40-50 ommatidia. Antenna approximately $1.7 \mathrm{~mm}$ long.

Pronotum (Fig. 27) moderately slender, approximately 1.25 times as long as broad and about 1.05 times as broad as head; punctation similar to that of head; impunctate midline rather narrow to moderately broad; interstices without microsculpture.

Elytra (Fig. 27) short, approximately 0.55 times as long as pronotum; punctation fine, sparse, shallow, and often weakly defined. Hind wings completely reduced. Protarsi with pronounced sexual dimorphism.

Abdomen with very fine, somewhat indistinct, and not particularly dense punctation, that of tergite VII distinctly sparser than that of anterior tergites; interstices with fine microsculpture; posterior margin of tergite VII without palisade fringe; tergite VIII without sexual dimorphism, with weakly convex posterior margin.

$0^{*}$ : protarsomeres I-IV strongly dilated; sternites III-VI unmodified; sternite VII (Fig. 33) moderately transverse, symmetric, and with defined median impression of triangular shape posteriorly, this impression with cluster of numerous strongly modified, short and stout black setae, posterior margin distinctly concave in the middle; sternite VIII (Fig. 34) weakly transverse, symmetric, and with long median impression, on either side of middle with numerous moderately modified black setae, posterior excision broad and not very deep; aedeagus (Figs 28-30) approximately $1.1 \mathrm{~mm}$ long, almost symmetric, and with conspicuously long and straight ventral process, apical portion of dorsal plate thin, lamellate, and rather weakly sclerotized, basal portion of dorsal plate short and very thin, internal sac with pair of distinctly sclerotized, broad-based spines.

क : protarsomeres I-IV moderately dilated, much less so than in male; sternite VIII (Fig. 35) approximately $0.9 \mathrm{~mm}$ long, rather weakly oblong, and convexly produced posteriorly; tergite IX with median portion undivided and moderately short, posterior processes moderately long and slender; tergite X nearly twice as long as tergite IX in the middle (Fig. 31).

\section{Comparative notes:}

Based on the similar external and sexual characters, particularly the presence of a pair of spines in the internal sac and the shape of the ventral process of the aedeagus, L. bispinigerum is the adelphotaxon of L. bibaculatum from the same mountain. It is distinguished from this species by slightly smaller body size, the more strongly modified male sternite VII (posteriorly with more numerous modified setae, posterior concavity more distinct), the more strongly modified male sternite VIII (pubescence distinctly modified posteriorly, posterior excision deeper), the straight and relatively longer ventral process of the aedeagus, the shorter, more broadbased, and more strongly sclerotized spines in the internal sac of the aedeagus, and the shorter female tergite $\mathrm{X}$ in relation to the median portion of tergite IX.

\section{Distribution and natural history:}

The species was discovered in three geographically close localities near the Erlang Shan Pass in western Sichuan, where the specimens were sifted at elevations of 2600$2900 \mathrm{~m}$.

\section{Lathrobium bihastatum sp. $\mathrm{n}$. (Figs 36-43)}

\section{Type material:}

Holotype $0^{\star}$ : "CHINA: W-Sichuan, Ya'an Pref., Fulin Co., Daxiang Ling, Pass N / Hanyuanjie $51 \mathrm{~km} \mathrm{NNE}$ Shimian, smal [sic] stream, 29.39N, 102.37E, $2300 \mathrm{~m}$, 10.VII.1999, leg. A. Pütz / Holotypus ơ Lathrobium bihastatum sp. n., det. V. Assing 2012" (cAss). Paratypes: 2 + ㅇ: same date as holotype (cPüt); 1 : : "CHINA W. Sichuan (Ya'an Pref., Fulin Co.) Daxiang Ling, road Hanyuanjie-Sipin, $51 \mathrm{~km}$ NNE Shimian, $2300 \mathrm{~m}$, $29^{\circ} 39 \mathrm{~N} 102^{\circ} 37 \mathrm{E}$ (river bank) 10.VII.1999 D. W. Wrase" (cSch).

\section{Etymology:}

The specific epithet (Latin, adjective: armed with two spears) refers to the presence of two long sclerotized spines in the internal sac of the aedeagus. 


\section{Description:}

Species of moderate size. Body length $8.0 \mathrm{~mm}\left(0^{*}\right), 7.5-$ $8.2 \mathrm{~mm}$ ( 9 ); length of forebody $3.6 \mathrm{~mm}\left(\mathrm{o}^{*}\right), 3.2-3.4 \mathrm{~mm}$ ( 9 ). Coloration: body brown to blackish; legs and antennae reddish.

Head (Fig. 36) approximately as broad as long; punctation moderately coarse and moderately dense, sparser in median dorsal portion; interstices with distinct microreticulation. Eyes weakly convex, approximately one third the length of postocular region in dorsal view, and composed of approximately 40-50 ommatidia. Antenna 1.8$2.0 \mathrm{~mm}$ long.

Pronotum (Fig. 36) moderately slender, approximately 1.25 times as long as broad and 1.05-1.10 times as broad

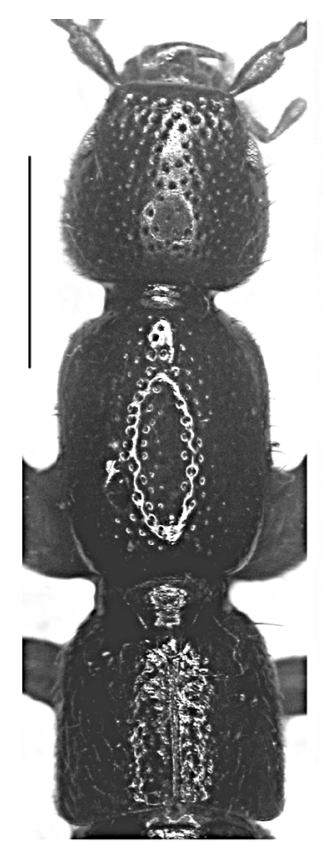

36

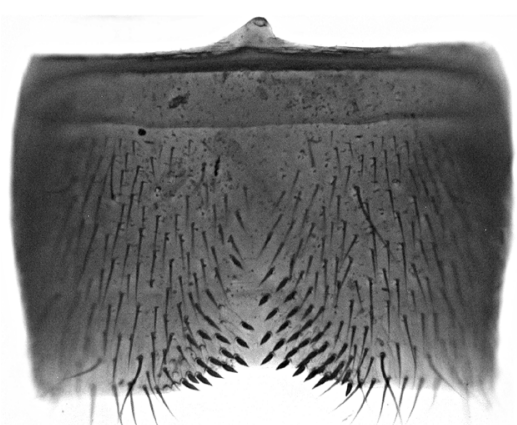

33

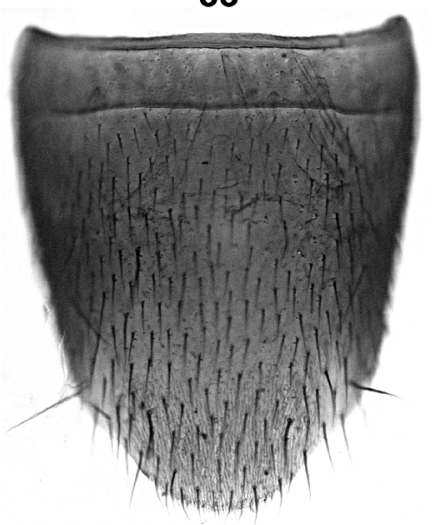

32

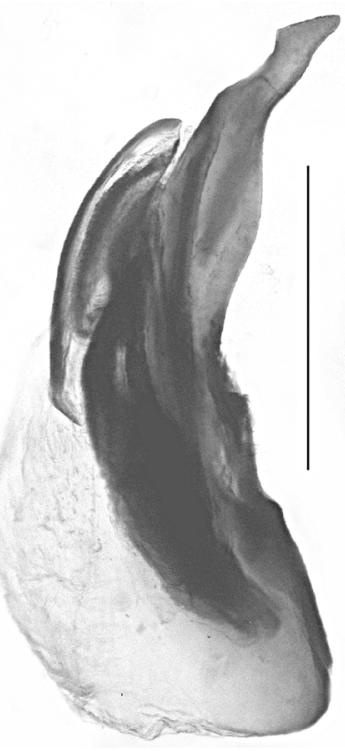

39

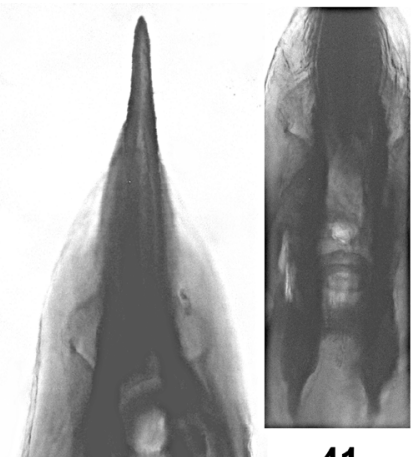

41

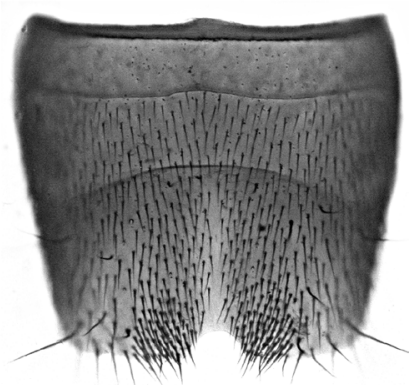

38

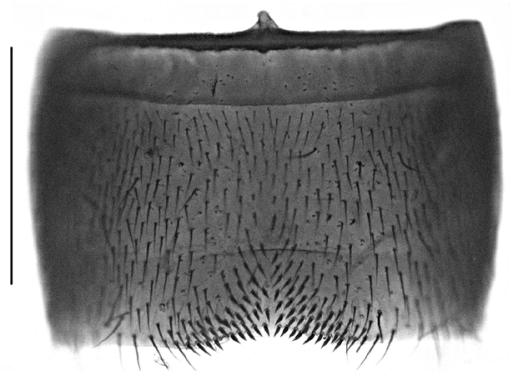

37

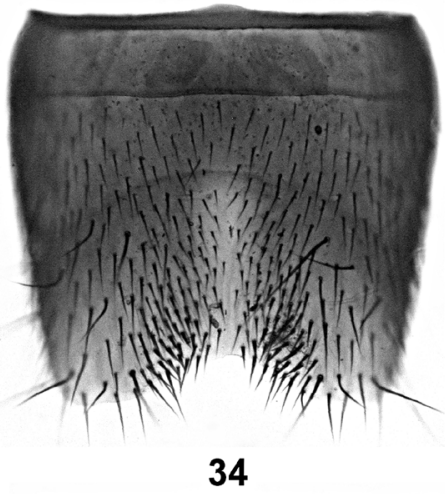

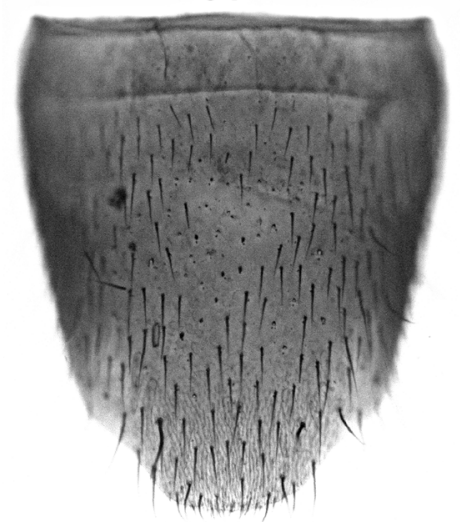

35

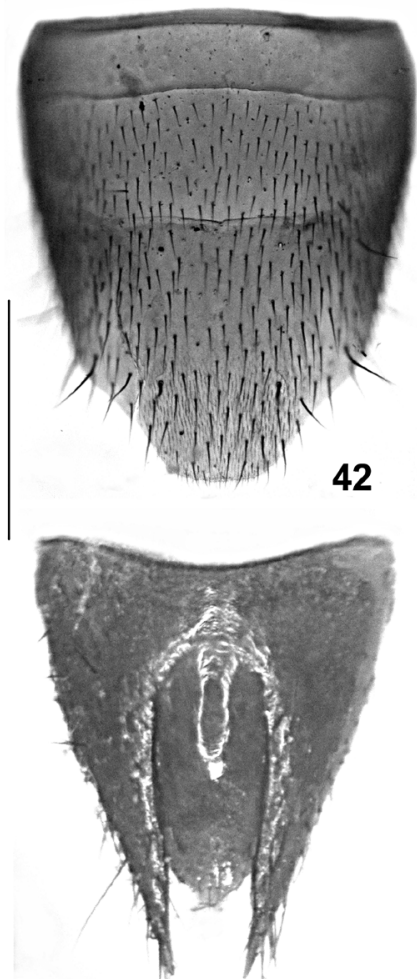

43

Figs 32-43: Lathrobium bibaculatum sp. n. (32), L. bispinigerum sp. n. (33-35), and L. bihastatum sp. n. (36-43): female sternite VIII $(32,35,42)$; male sternite VII $(33,37)$; male sternite VIII $(34,38)$; forebody $(36)$; aedeagus in lateral and in ventral view $(39-40)$; internal structures of aedeagus in dorsal view (41); female tergites IX-X (43). Scale bars: 36: $1.0 \mathrm{~mm}$; 32-35, 37-43: 0.5 mm. 
as head; punctation similar to that of head; impunctate midline moderately broad; interstices without microsculpture.

Elytra (Fig. 36) short, approximately 0.55 times as long as pronotum; punctation fine, shallow, and rather weakly defined. Hind wings completely reduced. Protarsi with pronounced sexual dimorphism.

Abdomen with moderately fine and very dense punctation, that of tergite VII noticeably sparser than that of anterior tergites; interstices with fine microsculpture; posterior margin of tergite VII without palisade fringe; tergite VIII with weakly pronounced sexual dimorphism.

$\sigma^{\text {t: }}$ protarsomeres I-IV strongly dilated; tergite VIII with weakly convex posterior margin; sternites III-VI unmodified; sternite VII (Fig. 37) moderately transverse, symmetric, and with median impression of triangular shape posteriorly, this impression with cluster of distinctly modified, short and stout black setae, posterior margin weakly concave in the middle; sternite VIII (Fig. 38) noticeably transverse, symmetric, and with shallow median impression, on either side of middle with cluster of weakly modified dark setae posteriorly, posterior excision small and of semi-circular shape; aedeagus (Figs 39-41) approximately $1.2 \mathrm{~mm}$ long, symmetric, and with ventral process of distinctive shape, apical portion of dorsal plate lamellate and moderately sclerotized, basal portion of dorsal plate short, internal sac with pair of distinctly sclerotized long spines.

ㅇ: protarsomeres I-IV moderately dilated, much less so than in male; posterior margin of tergite VIII weakly and obtusely pointed in the middle; sternite VIII (Fig. 42) approximately $1 \mathrm{~mm}$ long, moderately oblong, and convexly produced posteriorly; tergite IX with median portion undivided and moderately short, posterior processes moderately long and slender; tergite X much longer than tergite IX in the middle (Fig. 43).

\section{Comparative notes:}

Based on the male and female sexual characters, particularly the presence of a pair of sclerotized spines in the internal sac of the aedeagus, L. bihastatum undoubtedly belongs to the L. bibaculatum group. The similarly derived morphology of the aedeagus (somewhat spearshaped ventral process, rather massive internal spines), as well as the similar modifications of the male sternites VII and VIII suggest that it is the adelphotaxon of L. erlangense Peng \& LI, in press from the Erlang Shan, from which it is distinguished by larger body size, the stouter ventral process of the aedeagus, and by the posteriorly more broadly produced female sternite VIII.

\section{Distribution and natural history:}

The type locality is situated to the north-northeast of Shimian (western Sichuan) in the Daxiang Ling, where the species is probably endemic. The specimens were collected on a stream bank at an altitude of $2300 \mathrm{~m}$.

\section{Lathrobium aspinosum sp. n. \\ (Figs 44-51}

Type material:

Holotype ơ: "CHINA: W-Sichuan 1999, Yaan Prefecture, Tianquan Co., E Erlangshan Pass, 2900 m, 9 km SE Luding, $29^{\circ} 52 \mathrm{~N}, 102^{\circ} 18 \mathrm{E}$, Gesiebe, 20.VI., leg. M. Schülke / Holotypus ơ Lathrobium aspinosum sp. n., det. V. Assing 2012" (cSch). Paratypes: 1 \%: "CHINA: W-Sichuan 1999, Ganzi Tibet. Aut. Pref., Luding Co., W Erlangshan-Pass, $2600 \mathrm{~m}, 7 \mathrm{~km}$ SSE Luding, $29^{\circ} 51^{\prime} \mathrm{N}, 102^{\circ} 15^{\prime} \mathrm{E}$, Laubstreu, Pilze, 29.VI., leg. M. Schülke" (cSch); 1 ○": "CHINA: W-Sichuan 1999, Ganzi Tibet. Aut. Pref., Luding Co., W Erlang Shan Pass, 2900 m, $29^{\circ} 51 \mathrm{~N}, 102^{\circ} 17 \mathrm{E}$, Weiden + Moos, Blockhalde, 21.VI., leg. M. Schülke" (cSch, cAss); 1 ㅇ: "CHINA: W-Sichuan, Yaan Prefecture, Tianquan Co., E Erlang Shan Pass / 2900 m, 22.VI.1999, 29.52.36N, 102.17.82E, leg. A. Pütz" (cPüt).

\section{Etymology:}

The specific epithet (Latin, adjective: without spines) refers to the absence of long sclerotized spines in the internal sac of the aedeagus.

\section{Description:}

Species of moderately large size, without evident sexual size dimorphism. Body length 8.4-9.5 mm; length of forebody 3.5-4.0 mm. Habitus as in Fig. 44. Coloration: body dark-brown to blackish; legs and antennae reddish.

Head (Fig. 45) as broad as long or weakly transverse, more or less distinctly dilated posteriorly; punctation moderately coarse and moderately dense, sparser in median dorsal portion; interstices with distinct microreticulation. Eyes weakly convex, slightly more that one fourth the length of postocular region in dorsal view and composed of approximately 50 ommatidia. Antenna approximately $2 \mathrm{~mm}$ long.

Pronotum (Fig. 45) moderately slender, approximately 1.25 times as long as broad and about 1.05 times as broad as head; punctation similar to that of head; impunctate midline rather narrow to moderately broad; interstices without microsculpture.

Elytra (Fig. 45) short, 0.51-0.55 times as long as pronotum; punctation shallow, moderately dense, and rather weakly defined. Hind wings completely reduced. Protarsi with pronounced sexual dimorphism.

Abdomen with fine and dense punctation, that of tergite VII only slightly sparser than that of anterior tergites; interstices with fine microsculpture; posterior 
margin of tergite VII without palisade fringe; tergite VIII without sexual dimorphism, with weakly convex posterior margin.

$\sigma^{*}$ : protarsomeres I-IV strongly dilated; sternites III-VI unmodified; sternite VII (Fig. 46) strongly transverse, symmetric, and with moderately modified short and dark setae in postero-median impression, posterior margin weakly concave in the middle; sternite VIII (Fig. 47) noticeably transverse, posteriorly with weakly defined cluster of weakly modified dark setae on either side of middle, and with shallow, broadly V-shaped posterior excision; aedeagus (Figs 48-49) approximately $1.5 \mathrm{~mm}$ long, symmetric, and with slender, subapically weakly
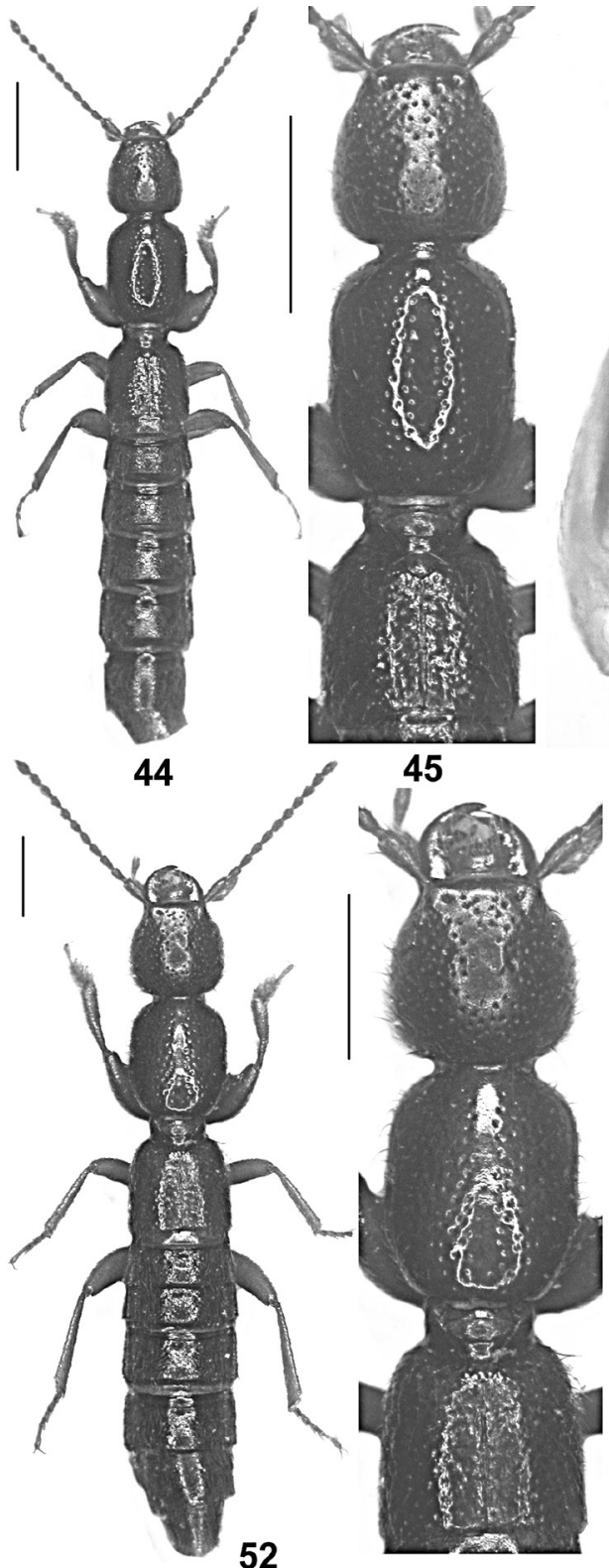

44

44

52

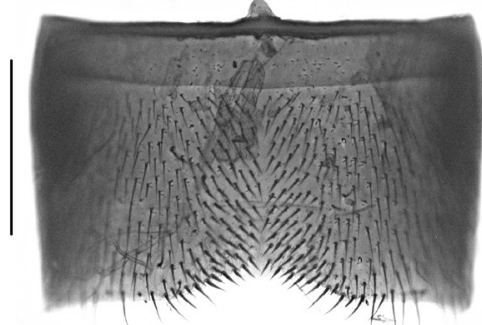

53

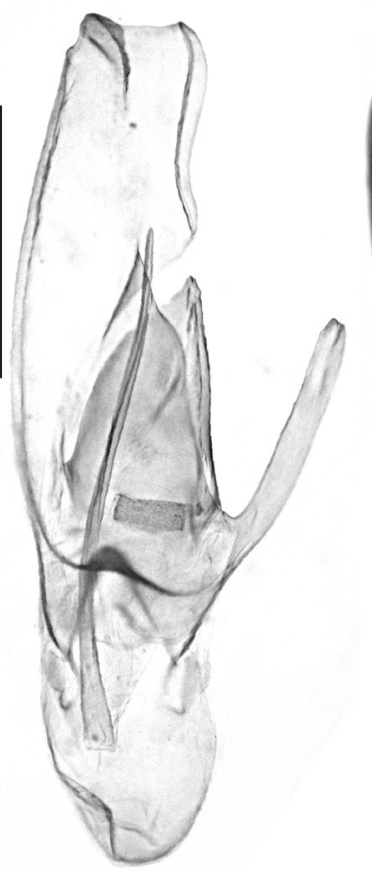

56

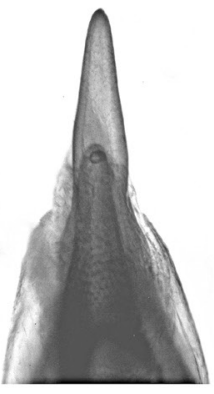

49

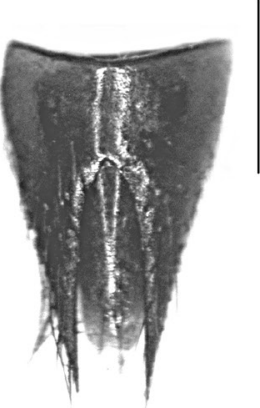

51

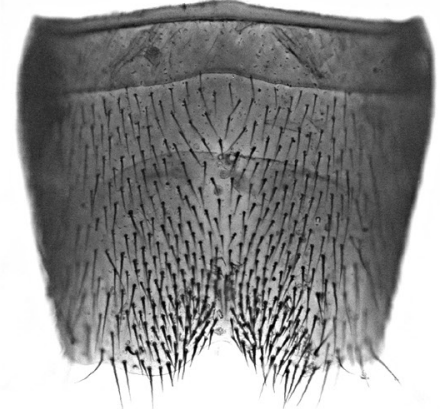

47

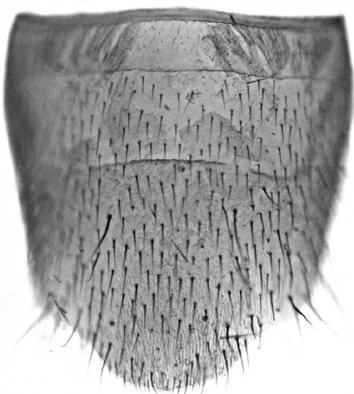

50

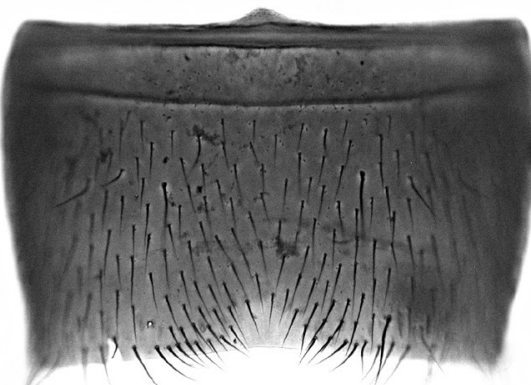

54

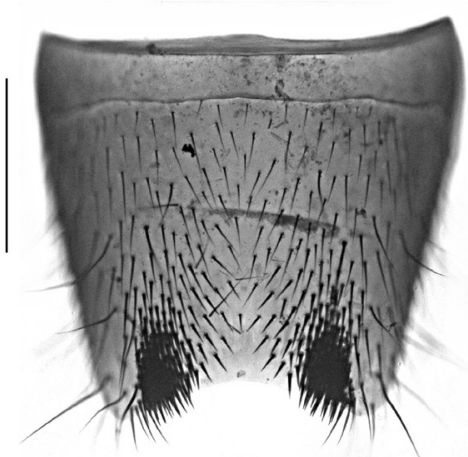

55

Figs 44-56: Lathrobium aspinosum sp. n. (44-51) and L. appendiculatum sp. n. (52-56): habitus $(44,52)$; forebody $(45,53)$; male sternite VII $(46,54)$; male sternite VIII $(47,55)$; aedeagus in lateral view $(48)$; apical portion of aedeagus in ventral view $(49)$; female sternite VIII (50); female tergites IX-X (51); aedeagus in latero-ventral view (56). Scale bars: 44-45, 52-53: 1.0 mm; 46-51, 54-56: $0.5 \mathrm{~mm}$. 
curved (lateral view), and apically acute ventral process, dorsal plate with very long and distinctly sclerotized apical portion and with very short basal portion; internal sac with dark membranous basal structures and with weakly sclerotized apical structure.

\%: protarsomeres I-IV moderately dilated, much less so than in male; sternite VIII (Fig. 50) 1.1-1.2 mm long, weakly oblong, and convexly produced posteriorly; tergite IX with median portion undivided and short, posterior processes long and slender; tergite $\mathrm{X}$ more than twice as long as tergite IX in the middle (Fig. 51).

\section{Comparative notes:}

The morphology of the aedeagus suggests that L. aspinosum belongs to the L. ensigerum group, which previously included three species from the Emei Shan (Assing et al. 2013) and with which the new species shares the long and large dorsal plate and the presence of an apical internal structure of the aedeagus. It is distinguished from the other representatives of this group by much larger eyes with more numerous ommatidia, the less slender head, the shapes and chaetotaxy of the male sternites VII and VIII, as well as by the morphology of the aedeagus. For illustrations of the species of the L. ensigerum group from the Emei Shan see Assing et al. (2013).

\section{Distribution and natural history:}

The species was discovered in three geographically close localities near the Erlang Shan Pass in western Sichuan, where the specimens were sifted at elevations of 2600 $2900 \mathrm{~m}$.

\section{Lathrobium appendiculatum sp. n. (Figs 52-56)}

Type material:

Holotype ơ: "CHINA - S Sichuan, 3000 m, pass N of Jinyang, Rhododendron, primary coniferous forest, 15-19. VI.2004, leg. R. Fabbri / Holotypus ơ Lathrobium appendiculatum sp. n., det. V. Assing 2012” (cAss).

\section{Etymology:}

The specific epithet (Latin, adjective) refers to the conspicuous lateral process of the aedeagus.

\section{Description:}

Species of moderately large size. Body length $8.8 \mathrm{~mm}$; length of forebody $4.4 \mathrm{~mm}$. Habitus as in Fig. 52. Coloration: head, pronotum, and abdomen blackish-brown; elytra blackish-brown with the suture, the posterior and the anterior margins dark-reddish; legs and antennae reddish.
Head (Fig. 53) as broad as long; punctation moderately coarse and moderately dense, sparser in median dorsal portion; interstices with distinct microreticulation. Eyes weakly convex, rather large, nearly half the length of postocular region in dorsal view and composed of $>50$ ommatidia. Antenna $2.4 \mathrm{~mm}$ long.

Pronotum (Fig. 53) rather broad, 1.22 times as long as broad and 1.04 times as broad as head; punctation similar to that of head, but somewhat coarser; impunctate midline moderately broad; interstices without microsculpture.

Elytra (Fig. 53) moderately short, 0.58 times as long as pronotum; punctation shallow and moderately dense. Hind wings completely reduced.

Abdomen with rather fine and moderately dense punctation, that of tergite VII noticeably sparser than that of anterior tergites; interstices with very shallow microsculpture, rather glossy; posterior margin of tergite VII without palisade fringe.

$\sigma^{\star}$ : protarsomeres I-IV strongly dilated; tergite VIII with distinctly convex posterior margin; sternites III-VI unmodified; sternite VII (Fig. 54) distinctly transverse, symmetric, with shallow postero-median impression, pubescence not distinctly modified, posterior margin broadly and very weakly concave; sternite VIII (Fig. 55) symmetric, weakly transverse, with extensive median impression, with pair of conspicuous clusters of extremely dense modified black setae posteriorly, and with broadly concave posterior margin; aedeagus (Fig. 56) $1.55 \mathrm{~mm}$ long, strongly asymmetric and strongly derived; ventral process asymmetric, with conspicuous lateral process, dorso-ventrally compressed, and apically somewhat truncate; dorsal plate with lamellate apical portion of asymmetrically triangular shape; internal sac with long and straight sclerotized spine.

ๆ: unknown.

\section{Comparative notes:}

Lathrobium appendiculatum is readily identified based on the conspicuous shape and chaetotaxy of the male sternite VIII and on the derived morphology of the aedeagus. Closer affiliations to any of the described Lathrobium species from China are not evident.

\section{Distribution and natural history:}

The type locality is situated to the north of Jinyang, southern Sichuan, not far from the border with Yunnan. The slightly teneral holotype was collected in a primary coniferous forest at an altitude of $3000 \mathrm{~m}$. 


\section{Lathrobium sp.}

Material examined:

1 9 : "CHINA - NW Sichuan, $20 \mathrm{~km}$ NW Maowen, $2150 \mathrm{~m}$, Jiuding Shan, coniferous wood, 7-28.VI.2004, leg. R. Fabbri” (cSch).

\section{Comment:}

The above specimen undoubtedly represents an undescribed species characterized by moderately small size (length of forebody $3.4 \mathrm{~mm}$ ), reddish-brown coloration, a slender head, distintly dilated protarsi, and a long and slender female tergite $\mathrm{X}$.

\section{Species from Chongqing}

Previously, only two species of Lathrobium, L. lobrathioides Assing, 2012 from the Jinfo Shan and L. trifidum Assing, in press from the Daba Shan in the border region with
Shaanxi, were known from Chongqing (Assing 2012b, in press). Below, two additional species from the Jinfo Shan are described.

\section{Lathrobium fortepunctatum sp. n.}

(Figs 57-64)

\section{Type material:}

Holotype $0^{\star}$ : "CHINA: SE Sichuan Jinfo Shan, $29^{\circ} 01 \mathrm{~N}$, 107²14E, 1750 m, 26.VI.1998, A. Smetana [C69] / 1998 China Expedition, J. Farkač, D. Král, J. Schneider \& A. Smetana / Holotypus o Lathrobium fortepunctatum sp. n., det. V. Assing 2012" (cAss). Paratype o : "CHINA: SE Sichuan Jinfo Shan, $29^{\circ} 01 \mathrm{~N}, 107^{\circ} 14 \mathrm{E}, 1800 \mathrm{~m}$, 27.VI.1998, A. Smetana [C70] / 1998 China Expedition, J. Farkač, D. Král, J. Schneider \& A. Smetana” (cSme).

\section{Etymology:}

The specific epithet (Latin, adjective) refers to the conspicuously coarse and dense punctation of the forebody.

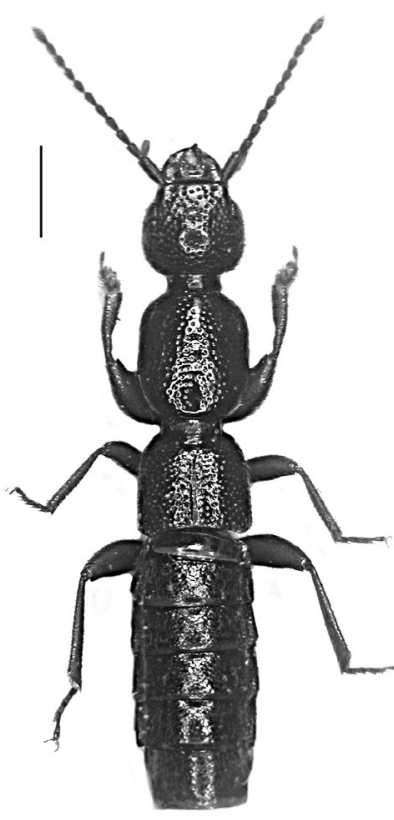

57

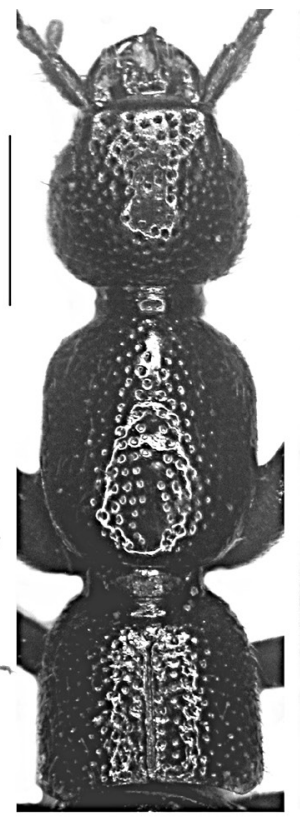

58

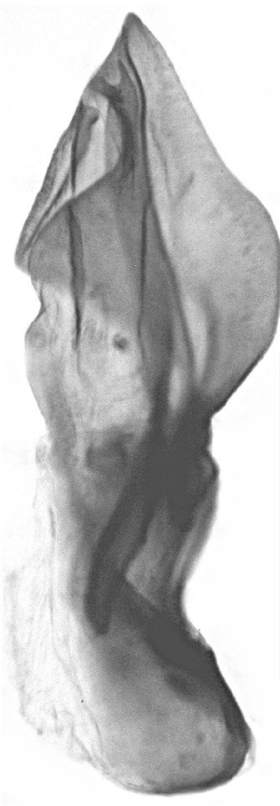

61

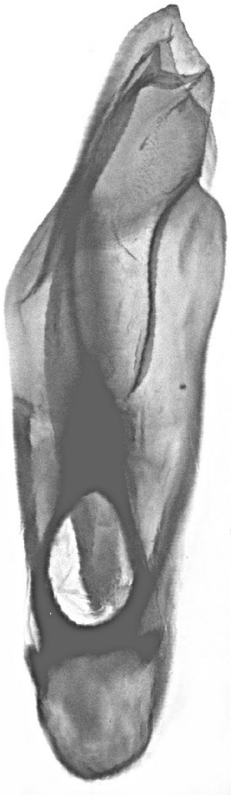

62

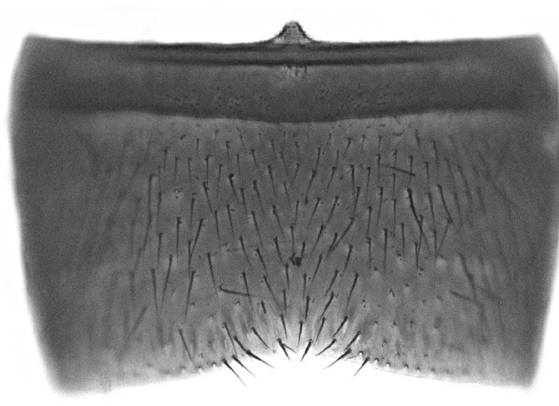

59

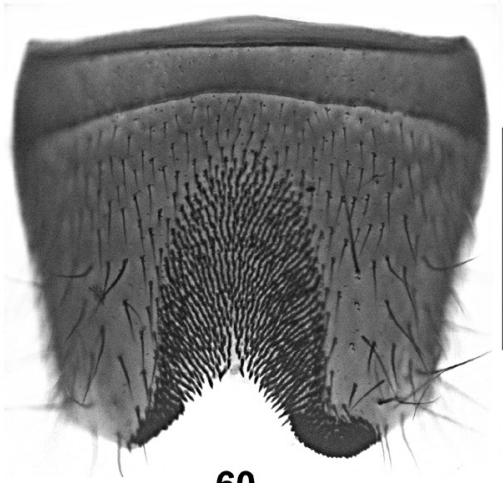

60

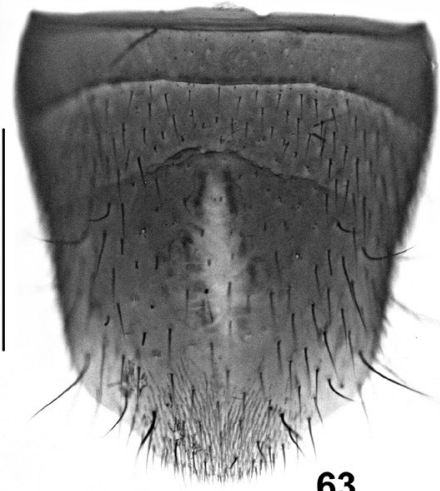

63

Figs 57-64: Lathrobium fortepunctatum sp. n.: habitus (57); forebody (58); male sternite VII (59); male sternite VIII (60); aedeagus in lateral and in ventral view (61-62); female sternite VIII (63); female tergites IX-X (64). Scale bars: 57-58: 1.0 mm; 59-64: 0.5 mm. 


\section{Description:}

Species of moderately large size; body length 7.7-8.0 mm; length of forebody 3.9-4.1 mm. Habitus as in Fig. 57. Coloration: body black; legs and antennae dark-brown.

Head (Fig. 58) transverse, 1.09 times as broad as long in holotype and 1.06 times as broad as long in paratype; punctation conspicuously coarse and dense, somewhat sparser in median dorsal portion; interstices glossy, with very shallow microreticulation. Eyes relatively large, approximately half as long as postocular region in dorsal view and composed of distinctly more than 50 ommatidia. Antenna 1.9-2.1 mm long.

Pronotum (Fig. 58) rather short, approximately 1.2 times as long as broad and 1.08 times as broad as head; punctation similar to that of head; impunctate midline narrow; interstices without microsculpture.

Elytra (Fig. 58) short, 0.53 times as long as pronotum; punctation dense, almost as coarse as that of head and pronotum. Hind wings completely reduced. Protarsi with pronounced sexual dimorphism.

Abdomen with rather fine and moderately dense punctation, that of tergite VII distinctly sparser than that of anterior tergites; microsculpture fine and shallow, interstices glossy; posterior margin of tergite VII without palisade fringe; tergite VIII with moderately pronounced sexual dimorphism.

$\mathrm{o}^{\star}$ : protarsomeres I-IV strongly dilated; posterior margin of tergite VIII weakly convex; sternites III-VI unmodified; sternite VII (Fig. 59) weakly modified, pubescence unmodified, posterior margin weakly concave; sternite VIII (Fig. 60) weakly transverse, strongly modified, slightly asymmetric, median impression pronounced, extensive, and with extremely numerous, extremely short, and conspicuously dense modified short black setae, on either side of the deep, broad, and slightly asymmetric posterior excision with conspicuous cluster of extremely dense and strongly modified, short and stout black setae, the two clusters of different shape and size; aedeagus (Figs 61-62) $1.2 \mathrm{~mm}$ long, strongly asymmetric; ventral process strongly asymmetric, with large lateral lamellae, and partly fused with the asymmetric dorsal plate; internal sac without sclerotized structures.

क : protarsomeres I-IV distinctly dilated, but less so than in male; posterior margin of tergite VIII obtusely pointed in the middle; sternite VIII (Fig. 63) $1.1 \mathrm{~mm}$ long, distinctly oblong, and with strongly convex posterior margin; tergite IX completely separated in the middle and with long postero-lateral processes; tergite $\mathrm{X}$ convex in cross-section, reaching anterior margin of tergite IX (Fig. 64).

\section{Comparative notes:}

This distinctive species is characterized particularly by its relatively broad and (in cross-section) weakly convex forebody, the conspicuously dense and coarse punctation of the forebody, the conspicuous shape and chaetotaxy of the male sternite VIII, the derived morphology of the strongly asymmetric aedeagus, the shape of the female sternite VIII, and the completely divided female tergite IX. Shared derived characters suggesting closer phylogenetic affiliations with other described species recorded from China were not found. From L. lobrathioides Assing, 2012, which, too, was described from the Jinfo Shan, L. fortepunctatum is readily distinguished by the much shorter elytra, smaller and less convex eyes, different coloration, and the completely different sexual characters. For illustrations of L. lobrathioides see Assing (2012b).

Distribution and natural history:

Lathrobium fortepunctatum is most likely endemic to the Jinfo Shan in Chongqing province (province status since 1997). The specimens were collected at altitudes of 1750 and $1800 \mathrm{~m}$.

\section{Lathrobium jinfoicum sp. n. (Figs 65-72)}

\section{Type material:}

Holotype $0^{*}$ : "CHINA: SE Sichuan Jinfo Shan, $29^{\circ} 01 \mathrm{~N}$, $107^{\circ} 14 \mathrm{E}, 1750$ m, 26.VI.1998, A. Smetana [C69] / 1998 China Expedition, J. Farkač, D. Král, J. Schneider \& A. Smetana / Holotypus ơ Lathrobium jinfoicum sp. n., det. V. Assing 2012" (cAss). Paratypes: 5 o 9 : same data as holotype; 2 우: “CHINA: SE Sichuan Jinfo Shan, $29^{\circ} 01 \mathrm{~N}, 107^{\circ} 14 \mathrm{E}, 1800 \mathrm{~m}, 27 . \mathrm{VI} .1998$, A. Smetana [C70] / 1998 China Expedition, J. Farkač, D. Král, J. Schneider \& A. Smetana" (cSme).

\section{Etymology:}

The specific epithet (Latin, adjective) is derived from the name of the mountain where the species is probably endemic.

\section{Description:}

Species of rather small size, without sexual size dimorphism; body length 5.0-5.8 mm; length of forebody 2.6$2.8 \mathrm{~mm}$. Habitus as in Fig. 65. Coloration: body brown to blackish-brown with slightly paler elytra; legs and antennae reddish.

Head (Fig. 66) indistinctly oblong, 1.01-1.05 times as long as broad; punctation moderately coarse and dense, sparser in median dorsal portion; interstices with fine microreticulation. Eyes relatively small, approximately one third as long as postocular region in dorsal view and 
composed of approximately 30 ommatidia. Antenna 1.4$1.5 \mathrm{~mm}$ long.

Pronotum (Fig. 66) approximately 1.25 times as long as broad and about 1.05 times as broad as head; punctation similar to that of head; impunctate midline moderately broad; interstices without microsculpture.

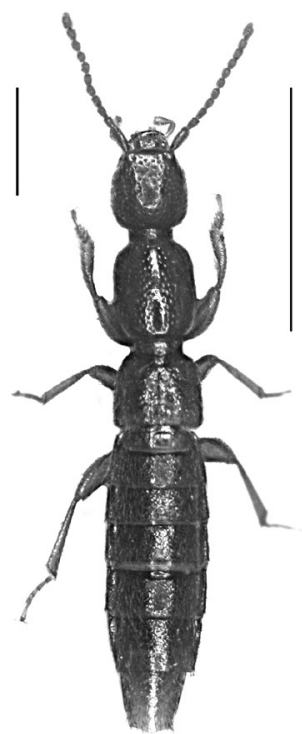

65

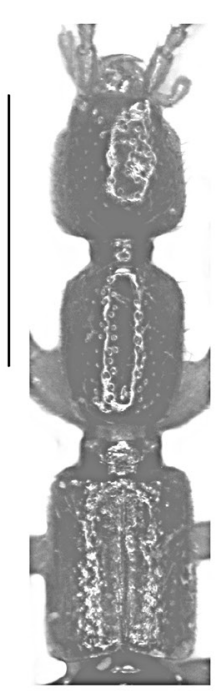

73

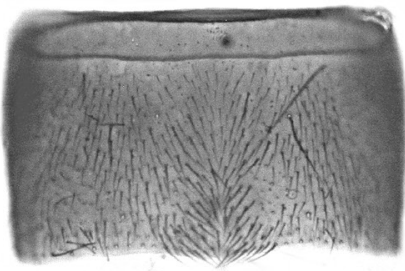

74

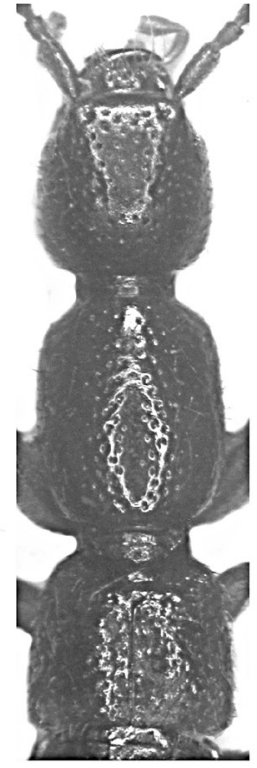

66

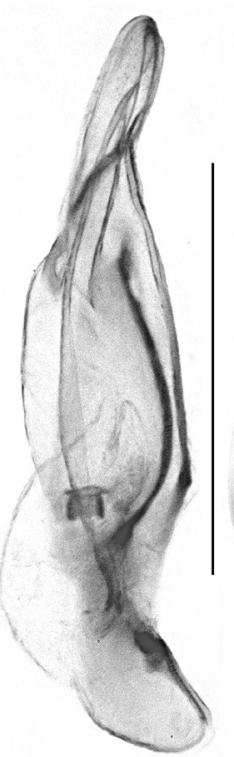

69
Elytra (Fig. 66) short, little more than 0.5 times as long as pronotum; punctation dense, shallow, and weakly defined. Hind wings completely reduced. Protarsi with weakly pronounced sexual dimorphism.

Abdomen with rather fine and dense punctation, that of tergite VII distinctly sparser than that of anterior

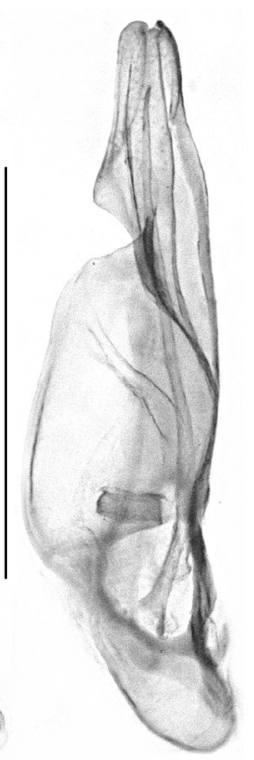

70

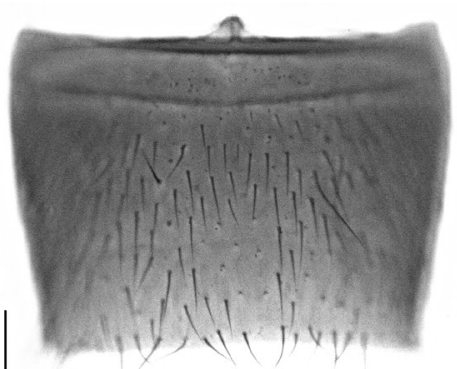

67

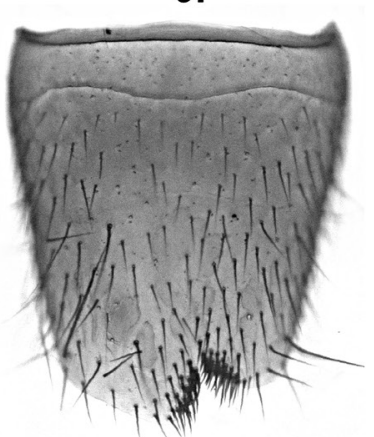

68

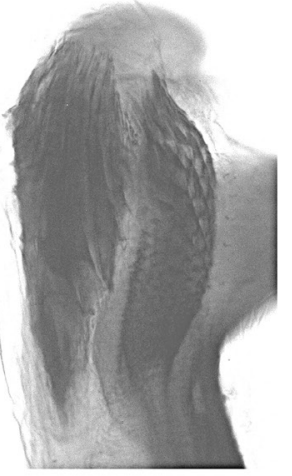

78

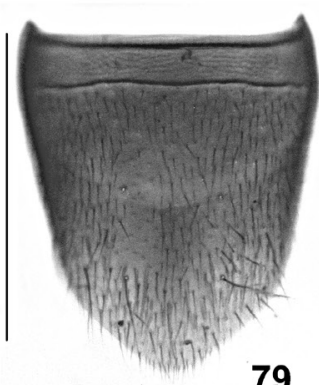

79

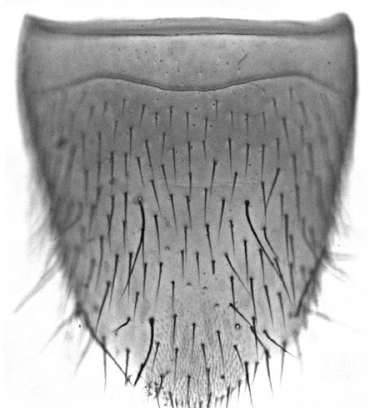

71

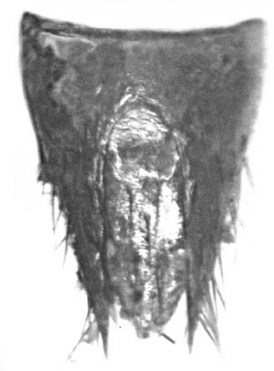

72

Figs 65-79: Lathrobium jinfoicum sp. n. (65-72) and L. imminutum sp. n. (73-79): habitus (65); forebody (66, 73); male sternite VII $(67,74)$; male sternite VIII $(68,75)$; aedeagus in lateral and in ventral view $(69-70,76-77)$; female sternite VIII $(71,79)$; female tergites IX-X (72); internal structures of aedeagus in lateral view (78). Scale bars: 65-66, 73: $1.0 \mathrm{~mm}$; 67-72, 74-77, 79: 0.5 mm; 78: $0.2 \mathrm{~mm}$. 
tergites; microsculpture fine and shallow, interstices rather glossy; posterior margin of tergite VII without palisade fringe; tergite VIII without evident sexual dimorphism, posterior margin obtusely pointed in the middle in both sexes.

$\sigma^{*}$ : protarsomeres I-IV moderately strongly dilated; sternites III-VI unmodified; sternite VII (Fig. 67) without appreciable modifications; sternite VIII (Fig. 68) oblong, posterior margin convex, with posterior excision in distinctly asymmetric position, margins of this excision with two small, but defined clusters of dense black setae; aedeagus (Figs 69-70) 0.9 mm long, slender, and distinctly asymmetric; ventral process asymmetric, apex of ventral process apparently fused with dorsal plate; internal sac with long and slender sclerotized spine.

9 : protarsomeres I-IV slightly less dilated than in male; sternite VIII (Fig. 71) $0.85 \mathrm{~mm}$ long, oblong, and with strongly convex posterior margin; tergite IX with short undivided median portion and with rather short postero-lateral processes; tergite $\mathrm{X}$ flat in cross-section, approximately 3 times as long as tergite IX in the middle (Fig. 72).

\section{Comparative notes:}

Lathrobium jinfoicum is readily distinguished from the syntopic L. fortepunctatum by external characters alone, particularly its distinctly smaller size, different coloration, less coarse punctation of the forebody, the more slender head, smaller eyes, more slender pronotum, and the less pronounced sexual dimorphism of the protarsi. In addition, both species are distinguished by the completely different sexual characters. Based on the generally similar external and the possibly synapomorphically derived sexual characters (shape and chaetotaxy of the male sternite VII, the oblong male sternite VIII with unmodified pubescence and convex posterior margin, the slender and asymmetric aedeagus with a long internal spine, the posteriorly strongly convex posterior margin of the female sternite VIII, and the morphology of the female tergites IX and X), L. jinfoicum appears to be closely allied to L. effeminatum Assing, in press from the Qinling Shan. It is distinguished from this species particularly by the asymmetric posterior excision of the male sternite VIII and by the shape of the aedeagus.

\section{Distribution and natural history:}

Like the syntopic L. fortepunctatum, L. jinfoicum is probably endemic to the Jinfo Shan in Chongqing province, where the specimens were collected at altitudes of 1750 and $1800 \mathrm{~m}$.

\section{Species from Beijing}

Micropterous species are unknown from Beijing province. Like L. wuesthoffi KocH, 1939, the only Lathrobium species previously recorded from Beijing (Assing in press), the new species below is macropterous.

\section{Lathrobium imminutum sp. $\mathrm{n}$.}

(Figs 73-79)

Type material:

Holotype o": "CHINA: BEIJING distr., Yan Shan, Dongling Mts (1400 m), Xiaolongmen, 15.-16.VI.2001, Hlaváč \& Cooter lgt / Holotypus ơ Lathrobium imminutum sp. n., det. V. Assing 2012" (cAss). Paratype + : same data as holotype (cAss).

\section{Etymology:}

The specific epithet is the past participle of the Latin verb imminuere (to reduce) and refers to the small body size.

\section{Description:}

Conspicuously small species; body length 4.0-4.2 mm; length of forebody 2.1-2.2 mm. Coloration: head and pronotum blackish-brown; elytra yellowish to yellowish brown posteriorly and more or less extensively infuscate anteriorly; abdomen blackish; legs and antennae palereddish.

Head (Fig. 73) oblong, nearly 1.1 times as long as broad; punctation moderately coarse and moderately dense, somewhat sparser in median dorsal portion; interstices glossy, with very shallow microreticulation. Eyes relatively large, approximately half as long as postocular region in dorsal view, or nearly so, and composed of approximately 40-50 ommatidia. Antenna 1.2-1.3 mm long.

Pronotum (Fig. 73) slender, approximately 1.3 times as long as broad and about 0.95 times as broad as head; punctation similar to that of head; impunctate midline rather broad; interstices without microsculpture.

Elytra (Fig. 73) long, 0.87-0.95 times as long as pronotum; punctation moderately dense, shallow, and weakly defined. Hind wings apparently fully developed. Protarsi with rather weakly pronounced sexual dimorphism.

Abdomen almost matt due to the very dense and fine punctation; punctation of tergite VII slightly less dense than that of anterior tergites; posterior margin of tergite VII with palisade fringe; tergite VIII with pronounced sexual dimorphism.

$\sigma^{\star}$ : protarsomeres I-IV strongly dilated; posterior margin of tergite VIII weakly convex; sternites III-VI unmodified; sternite VII (Fig. 74) relatively strongly transverse, 
posteriorly with shallow median impression, this impression with cluster of rather weakly modified dark setae, posterior margin weakly concave, in the middle weakly convex; sternite VIII (Fig. 75) moderately transverse, symmetric, with cluster of weakly modified dark setae in the middle, and with deep V-shaped posterior excision, depth of this excision approximately two fifths of the length of sternite; aedeagus (Figs 76-78) small, $0.6 \mathrm{~mm}$ long, symmetric, and with short, laterally compressed, and somewhat curved ventral process; dorsal plate not noticeable; internal sac with dark clusters of semi-transparent spines.

ㅇ: protarsomeres I-IV distinctly dilated, slightly less so than in male; posterior margin of tergite VIII (Fig. 79) distinctly pointed in the middle; sternite VIII $0.6 \mathrm{~mm}$ long, weakly oblong, and with strongly convex posterior margin; tergite IX with very short median portion and with long and slender postero-lateral processes; tegite $\mathrm{X}$ weakly convex in cross-section, nearly four times as long as tergite IX in the middle.

\section{Comparative notes:}

This species is readily distinguished from all other Lathrobium species recorded from China by its conspicuously small body size alone. In general appearance it resembles macropterous specimens of the trans-Palaearctic L. longulum GravenHorst, 1802 from which it is distinguished by the even slightly smaller body size and by the completely different primary and secondary sexual characters. For illustrations of L. longulum see Assing (2012a).

Distribution and natural history:

Lathrobium imminutum is currently known only from the Yan Shan in Beijing province, but the long elytra and apparently fully developed hind wings suggest that the species may be more widespread. The type specimens were collected at an altitude of $1400 \mathrm{~m}$, together with the widespread L. wuesthoffi КосH, 1939.

\section{Species from Zhejiang}

As many as 16 micropterous Lathrobium species have been described from Zhejiang province, five from Baishanzu Natural Reserve, three from the Jiulong Shan (one of them recorded also from Majian), four from the Longwang Shan, two from the Tianmu Shan (one of them also in the Longwang Shan), two from Wuyanling, and one from Linglong Shan (Assing in press). An additional unnamed species was recorded from Longwang Shan (Peng et al. 2012a).

\section{Lathrobium parvitergale sp. $\mathrm{n}$. \\ (Figs 80-86)}

\section{Type material:}

Holotype ơ: "CHINA: Zhejiang [CH07-37], Tianmu Shan, pass $25 \mathrm{~km}$ NNW Linan, 620-820 m, 30² $25^{\prime} 40^{\prime \prime} \mathrm{N}$, $119^{\circ} 35^{\prime} 30^{\prime \prime E}$, creek valley with bamboo and mixed forest, litter, sifted, 16.VI.2007, M. Schülke / Holotypus ơ Lathrobium parvitergale sp. n., det. V. Assing 2012" (cAss). Paratype + : same data as holotype (cSch).

\section{Etymology:}

The specific epithet (Latin, adjective) refers to the conspicuously small female tergite $\mathrm{X}$.

\section{Description:}

Large species; body length $12.0 \mathrm{~mm}\left(\sigma^{*}\right), 11.5 \mathrm{~mm}$ ( ( ); length of forebody $5.5 \mathrm{~mm}\left(\sigma^{\star}\right), 5.3 \mathrm{~mm}$ ( ㅇ $)$. Coloration: body black; legs and antennae dark-brown.

Head (Fig. 80) moderately transverse, approximately 1.05 times as broad as long; punctation moderately coarse, rather dense in lateral and posterior portions, rather sparse in median and anterior dorsal portions; interstices glossy, with very fine and very shallow microreticulation. Eyes relatively large, approximately half as long as postocular region in dorsal view and composed of approximately 50 weakly defined ommatidia. Antenna 3.0-3.2 mm long.

Pronotum (Fig. 80) rather short, approximately 1.15 times as long as broad and 1.08 times as broad as head; punctation similar to that of head; impunctate midline very narrow; interstices without microsculpture.

Elytra (Fig. 80) short, approximately 0.52 times as long as pronotum; punctation dense, coarse, and rather defined. Hind wings completely reduced. Protarsi with rather weakly pronounced sexual dimorphism.

Abdomen with fine and dense punctation, that of tergite VII nearly as dense as that of anterior tergites; microsculpture fine and indistinct, visible only at high magnifications, interstices glossy; posterior margin of tergite VII without palisade fringe; tergite VIII without sexual dimorphism, posterior margin weakly convex in both sexes.

$0^{*}$ : protarsomeres I-IV strongly dilated; sternites III-VI unmodified; sternite VII (Fig. 81) strongly transverse and with small and shallow median impression posteriorly, this impression with few modified short black setae, posterior margin broadly concave; sternite VIII (Fig. 82) transverse, with oblong and somewhat asymmetric median impression, this impression posteriorly (anterior to posterior excision) with pronounced, defined, and asymmetric cluster of numerous distinctly modified, short and stout black setae; posterior exci- 
sion slightly asymmetric, rather deep and very narrow; aedeagus (Figs 83-84) $1.7 \mathrm{~mm}$ long and asymmetric; ventral process stout, short, and apically asymmetrically bilobed; dorsal plate distinctly sclerotized, with long, large, somewhat asymmetric, and apically acute apical portion and with short lamellate basal portion; internal sac with long, stout, curved, and strongly sclerotized apical spine.

ㅇ: protarsomeres I-IV distinctly dilated, but slightly less so than in male; posterior margin of sternite VIII (Fig. 85) $1.7 \mathrm{~mm}$ long, weakly oblong, posterior margin distinctly and convexly produced in the middle; tergite IX with long, undivided median portion and with short postero-lateral processes; tergite X small, only approximately half as long as tergite IX in the middle (Fig. 86). the long median portion of the female tergite IX, and the conspicuously small female tergite $\mathrm{X}$. It is distinguished from all other described species known from the Tianmu Shan and the adjacent Longwang Shan by its larger size alone. Lathrobium parvitergale shares the presence of an apical spine in the internal sac with most species from these mountain ranges, but the other sexual characters do not suggest closer phylogenetic affiliations with any of them. For illustrations of the described species recorded from Tianmu Shan and Longwang Shan see PENG et al. (2012a) and Watanabe (1999a, b).

\section{Distribution and natural history:}

The type locality is situated in the Tianmu Shan in Zhejiang province. The specimens were sifted from leaf litter in a mixed forest with bamboo at an altitude of 620-820 m.

\section{Comparative notes:}

This highly distinctive species is characterized particularly by its large size, dark coloration, and by the sexual characters, particularly the shape and chaetotaxy of the male sternite VIII, the morphology of the aedeagus (stout, short, and apically asymmetrically bilobed ventral process; shapes of dorsal plate and apical internal structure),

\section{Lathrobium sp.}

\section{Material examined:}

1 ㅇ: "CHINA: Zhejiang [CH07-36], West Tianmu Shan N.R., way to peak of immortals, $30^{\circ} 20^{\prime} 34^{\prime \prime} \mathrm{N}, 119^{\circ} 25^{\prime} 51^{\prime \prime E}$,

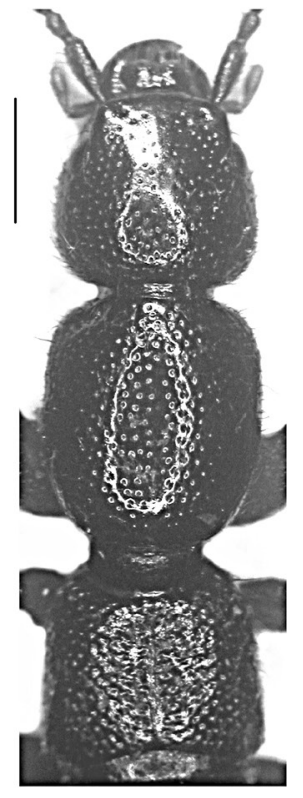

80

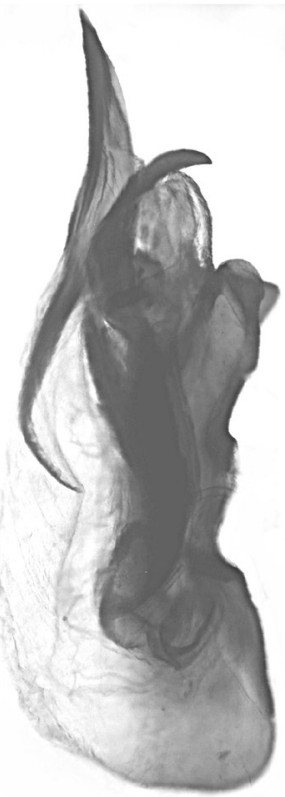

83

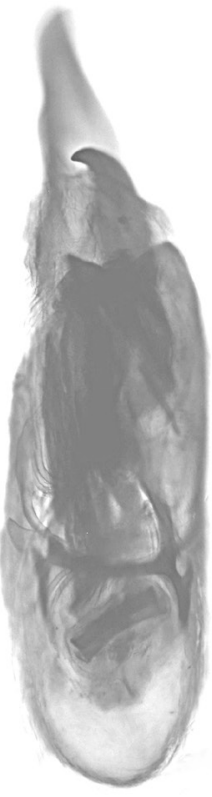

84

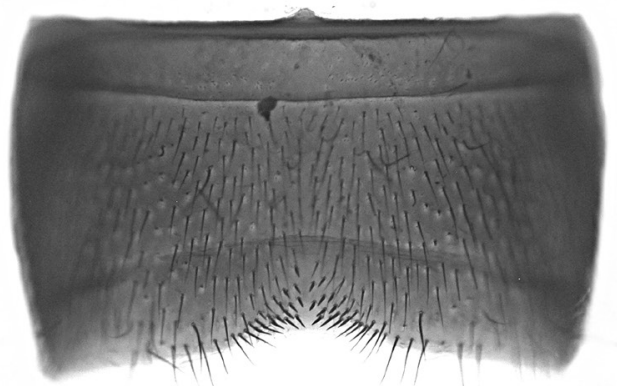

81

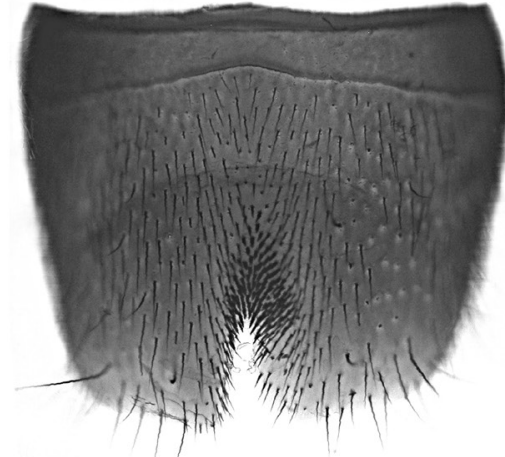

82

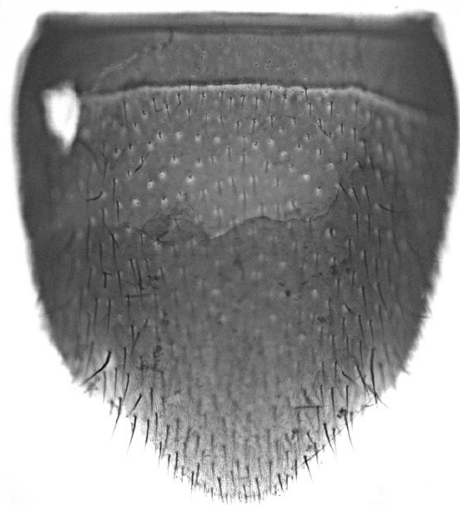

85

Figs 80-86: Lathrobium parvitergale sp. n.: forebody (80); male sternite VII (81); male sternite VIII (82); aedeagus in lateral and in ventral view (83-84); female sternite VIII (85); female tergites IX-X (86). Scale bars: 80: $1.0 \mathrm{~mm}$; 81-86: $0.5 \mathrm{~mm}$. 
1100-1200 m, prim. mixed forest, litter, moss, sifted, 15.VI.2007, M. Schülke” (cSch); 1 ㅇ: same data, but leg. A. Pütz (cPüt).

\section{Comment:}

Except for its slightly smaller body size, this evidently undescribed species is similar to L. parvitergale in external characters. It is distinguished, however, by the much shorter median portion of the female tergite IX and the much longer female tergite $\mathrm{X}$. The female terminalia are similar to those of the smaller L. tianmushanense Watanabe, 1999. For illustrations of L. tianmushanense see Peng et al. (2012a).

\section{Species from Fujian and Jiangxi}

Two Lathrobium species were previously known from Fujian, one from the Wuyi Shan and one from the Junzifeng Shan (Peng et al. 2012c). Not a single species had been recorded from Jiangxi. All four species described below were collected in the Wuyi Shan, three of them in Jiangxi and one in Fujian province.

\section{Lathrobium daicongchaoi PENG \& LI, 2012}

\section{Material examined:}

China: Fujian: 1 o $^{\star}, 1$ 아 , Wuyi Shan Nature Reserve, Sangan env., 900 m, 30.V.-12.VI.2001, leg. Hlaváč \& Cooter (cAss); 5 우 우, Wuyi Shan Nature Reserve, Guadun hill, 900-1300 m, 12.VI.2001, leg. Hlaváč \& Cooter (cAss).

\section{Comment:}

The original description of L. daicongchaoi is based on nine type specimens from "Fujian Prov./Wuyishan City / Guadun Village / $27^{\circ} 44^{\prime} \mathrm{N}, 117^{\circ} 37^{\prime} \mathrm{E}$, collected at an altitude of $1400 \mathrm{~m}$ (PENG et al. 2012c). The above specimens were found at, or close to, the type locality.

\section{Lathrobium barbiventre sp. $\mathrm{n}$.}

(Figs 87-91)

\section{Type material:}

Holotype $0^{\star}$ : "CHINA: FUJIAN prov., Wuyi Shan Nat. Res., Sangan env. (900 m) 30.v.-12.vi.2001, Hlaváč \& Cooter lgt. / Holotypus ơ Lathrobium barbiventre sp. n., det. V. Assing 2012" (cAss).

\section{Etymology:}

The specific epithet is an adjective derived from and composed of the Latin nouns barba (beard) and venter (abdomen). It alludes to the presence of clusters of modified setae on the male sternites V-VIII.

\section{Description:}

Rather large species of stout and somewhat depressed habitus; body length $10.5 \mathrm{~mm}$; length of forebody $4.9 \mathrm{~mm}$. Coloration: forebody black; abdomen blackishbrown; legs and antennae dark-brown.

Head (Fig. 87) distinctly transverse, 1.1 times as broad as long; punctation moderately coarse and rather dense, sparse in median dorsal portion; interstices with distinct fine microreticulation, with subdued shine. Eyes moderately small, approximately 0.4 times as long as postocular region in dorsal view and composed of distinctly more than 50 ommatidia. Antenna $2.5 \mathrm{~mm}$ long.

Pronotum (Fig. 87) broad, 1.16 times as long as broad and 1.07 times as broad as head; punctation slightly coarser than that of head; impunctate midline narrow; interstices without microsculpture.

Elytra (Fig. 87) short, 0.53 times as long as pronotum; punctation rather coarse, dense, and defined.

Abdomen with fine and moderately dense punctation, that of tergite VII somewhat sparser than that of anterior tergites; microsculpture fine and shallow; posterior margin of tergite VII without palisade fringe.

$\sigma^{\text {* }}$ : protarsomeres I-IV moderately strongly dilated; tergite VIII with weakly concave posterior margin; sternites $\mathrm{V}$ and VI with pronounced subcircular median clusters of strongly modified, short and stout black setae; sternite VII (Fig. 88) strongly transverse, with moderately extensive and shallow median impression posteriorly, this impression with cluster of modified, short and stout black setae, posterior margin broadly and weakly concave; sternite VIII (Fig. 89) moderately transverse, weakly asymmetric, and with pronounced, extensive, and weakly asymmetric median impression, this impression with distinctly modified short and stout black setae posteriorly, posterior excision weakly asymmetric, small, and somewhat U-shaped; aedeagus (Figs 90-91) $1.6 \mathrm{~mm}$ long and asymmetric; ventral process stout, asymmetric, and apically acute; dorsal plate with large and lamellate apical portion, and with short, narrow, and thin basal portion; internal sac with two sclerotized spines of different shapes, and with additional membranous structures.

o : unknown

\section{Comparative notes:}

Based on the synapomorphically derived shapes and chaetotaxy of the male sternites VII and VIII, the synapomorphically derived chaetotaxy of the male sternites V-VI, and the similarly derived morphology of the aedeagus 
(presence of two sclerotized spines of different shapes in the internal sac; morphology of the dorsal plate), L. barbiventre is closely allied to L. daicongchaoi from the same mountain range and L. fujianense PENG \& LI, 2012 from the Junzifeng Shan. It is distinguished from them by the male sexual characters, from L. daicongchaoi additionally by larger body size.

\section{Distribution and natural history:}

Lathrobium barbiventre is most likely endemic to the Wuyi Shan, where the holotype was found in a locality to the southwest of the Huanggang Shan, Fujian, at an altitude of $900 \mathrm{~m}$, together with L. daicongchaoi.

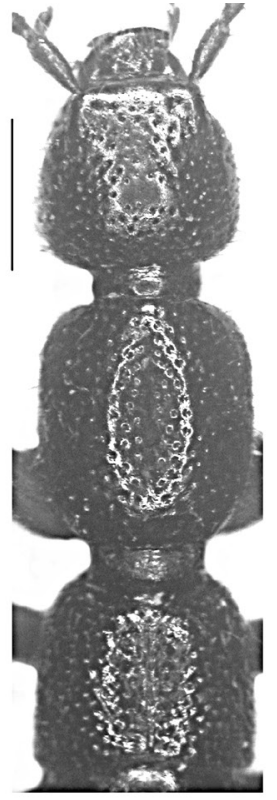

87

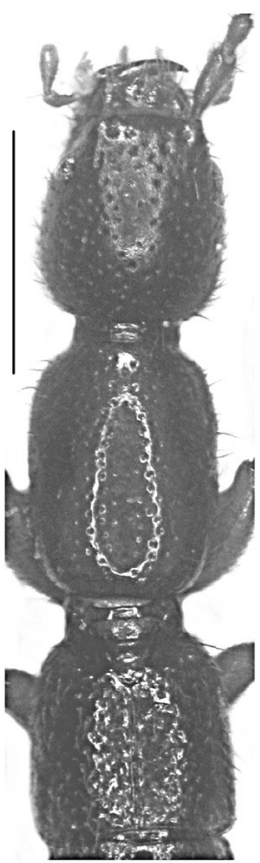

92

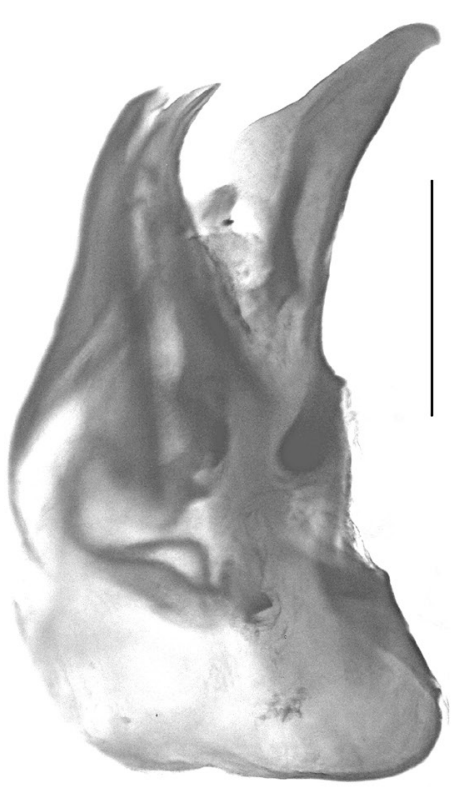

90

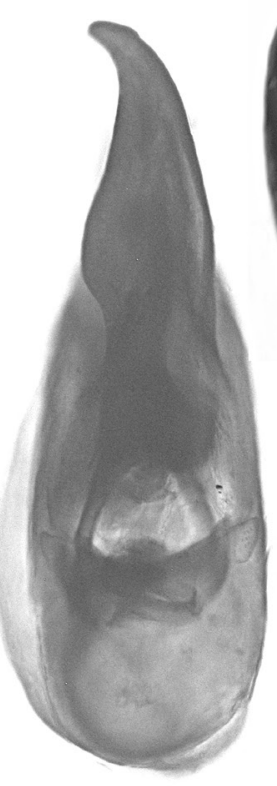

91

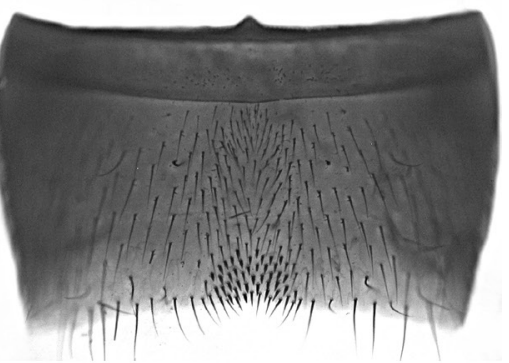

88
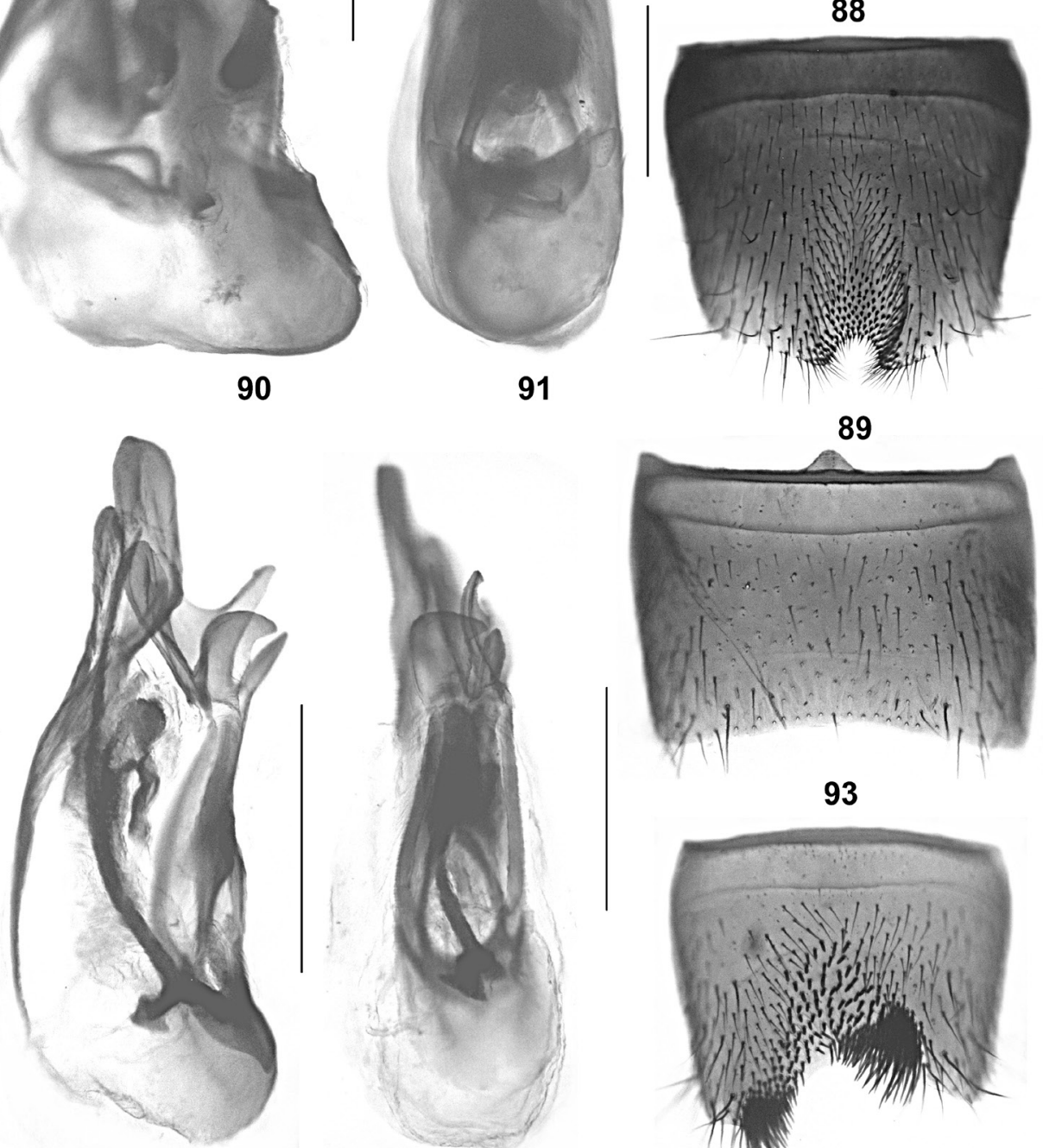

95

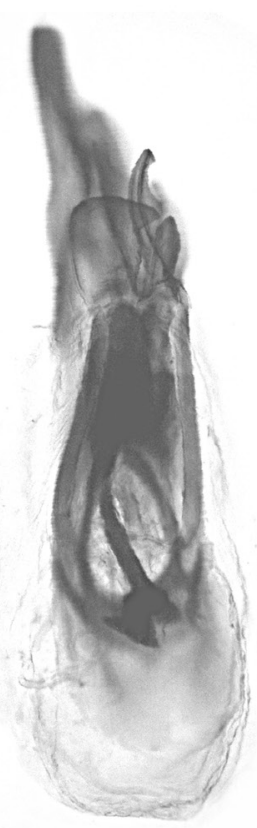

96
89

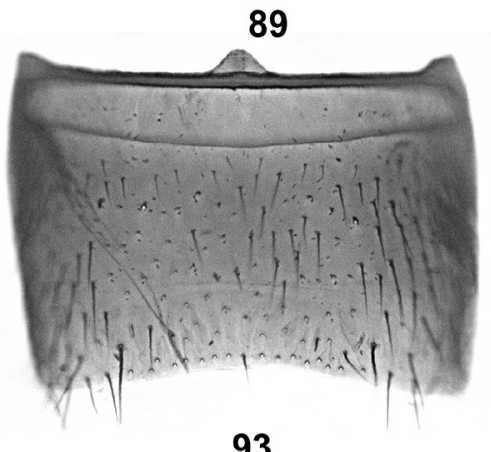

93

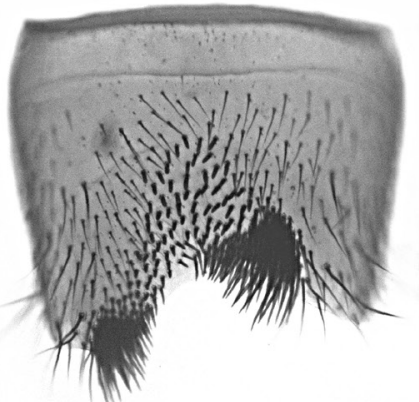

94

Figs 87-96: Lathrobium barbiventre sp. n. (87-91) and L. depravatum sp. n. (92-96): forebody (87, 92); male sternite VII (88, 93); male sternite VIII $(\mathbf{8 9}, \mathbf{9 4})$; aedeagus in lateral and in ventral view (90-91, 95-96). Scale bars: 87, 92: 1.0 mm; 88-91, 93-96: 0.5 mm. 


\section{Etymology:}

The specific epithet is the past participle of the Latin verb depravare (to deform) and refers to the asymmetries of the male and female sexual characters.

\section{Description:}

Species of relatively small size, without sexual size dimorphism; body length $6.2-6.5 \mathrm{~mm}$; length of forebody $3.2 \mathrm{~mm}$. Coloration: body reddish-brown with slightly darker head; legs and antennae reddish.

Head (Fig. 92) distinctly oblong, 1.12-1.14 times as long as broad; punctation rather coarse and moderately dense, sparser in median dorsal portion; interstices with distinct fine microreticulation, silk-matt. Eyes small, approximately one fourth as long as postocular region in dorsal view and composed of approximately 40 ommatidia. Antenna $1.7 \mathrm{~mm}$ long.

Pronotum (Fig. 92) slender, approximately 1.35 times as long as broad and approximately as broad as head; punctation similar to that of head; impunctate midline moderately broad; interstices without microsculpture.

Elytra (Fig. 92) short, approximately 0.55 times as long as pronotum; punctation rather shallow and weakly defined. Metatibia with weak sexual dimorphism; protarsi with weakly pronounced sexual dimorphism.

Abdomen slender; punctation moderately fine and not particularly dense, that of tergite VII somewhat sparser than that of anterior tergites; microsculpture fine and shallow, interstices rather glossy; posterior margin of tergite VII without palisade fringe; tergite VIII with sexual dimorpism.

$\sigma^{*}$ : protarsomeres I-IV moderately strongly dilated; metatiba with small ventral dilatation at apical third; tergite VIII weakly transverse, posterior margin truncate; sternites III-VI unmodified; sternite VII (Fig. 93) without appreciable modifications, except for the weakly concave posterior margin; sternite VIII (Fig. 94) distinctly transverse, strongly asymmetric and with conspicuous chaetotaxy, with extensive median impression, this impression with a cluster of numerous strongly modified short and stout black setae, posteriorly with two pronounced clusters of strongly modified long black setae, these clusters of different shapes and in asymmetric position, posterior excision large, deep, and strongly asymmetric; aedeagus (Fig. 95-96) $1.1 \mathrm{~mm}$ long, strongly asymmetric, and of highly distinctive morphology; ventral process asymmetric and apically divided into two lobes of different shapes; dorsal plate very large, asymmetric, and apically divided into two lobes of different shapes; internal sac with long and curved sclerotized spine and with additional apical spine of characteristic shape.
क : protarsomeres I-IV nearly as dilated as in male; tergite VIII (Fig. 112) oblong and with weakly concave posterior margin; sternite VIII (Fig. 97) 0.9 mm long, oblong, and asymmetric, posterior margin convexly produced in the middle and on either side of this convex projection with concave excision of different shape and in asymmetric position; tergite IX conspicuously short and asymmetric, median portion short and undivided, but partly with median suture, postero-lateral process short, but of different lengths, the left process distinctly shorter than the right one; tergite X broad, nearly flat in cross-section, slightly more than twice as long as tergite IX in the middle (Fig. 113).

\section{Comparative notes:}

Lathrobium depravatum is one of the most distinctive species known from China. Externally, it is characterized particularly by the distinctly oblong head. The most conspicuous male sexual characters are the modified metatibiae, the remarkable shape and chaetotaxy of sternite VIII and the intricate morphology of the aedeagus. Even the female is characterized by unique sexual characters, particularly the asymmetric shape of the posterior margin of sternite VIII and the asymmetric and conspicuously short tergite IX. Synapomorphies suggesting closer affiliations with any of the geographically close congeners were not found.

\section{Distribution and natural history:}

Lathrobium depravatum is probably endemic to the Wuyi Shan. The specimens were found in the Huanggang Shan in Jiangxi province, at an altitude of 1800-2050 m. Lathrobium cornigerum and L. wuyicum were collected in the same sample.

\section{Lathrobium cornigerum sp. $\mathrm{n}$. \\ (Figs 98-102)}

\section{Type material:}

Holotype ơ: "CHINA: JIANGXI prov., Wuyi Shan Nat. Res., Huangganshan [sic], (1800-2050 m), 5.vi.2001, Hlaváč \& Cooter lgt / Holotypus ơ Lathrobium cornigerum sp. n., det. V. Assing 2012" (cAss).

\section{Etymology:}

The specific epithet (Latin, adjective: with antlers) alludes to the two apical horn-like processes of the dorsal plate of the aedeagus.

\section{Description:}

Large species of stout and somewhat depressed habitus; body length $12.0 \mathrm{~mm}$; length of forebody $5.9 \mathrm{~mm}$. Coloration: body black; legs and antennae dark-brown.

Head (Fig. 98) distinctly transverse, 1.15 times as broad as long; punctation moderately coarse and moderately 
dense, sparse in median dorsal portion; interstices with distinct fine microreticulation, with subdued shine. Eyes rather large, slightly less than half as long as postocular region in dorsal view and composed of distinctly more than 50 ommatidia. Antenna $3.1 \mathrm{~mm}$ long.

Pronotum (Fig. 98) broad, 1.12 times as long as broad and 1.05 times as broad as head; punctation distinctly coarser than that of head; impunctate midline narrow; interstices without microsculpture.

Elytra (Fig. 98) very short, 0.47 times as long as pronotum; punctation rather coarse and defined.

Abdomen with very fine and moderately dense punctation, that of tergite VII somewhat sparser than that of anterior tergites; microsculpture fine and shallow, interstices rather glossy; posterior margin of tergite VII without palisade fringe.

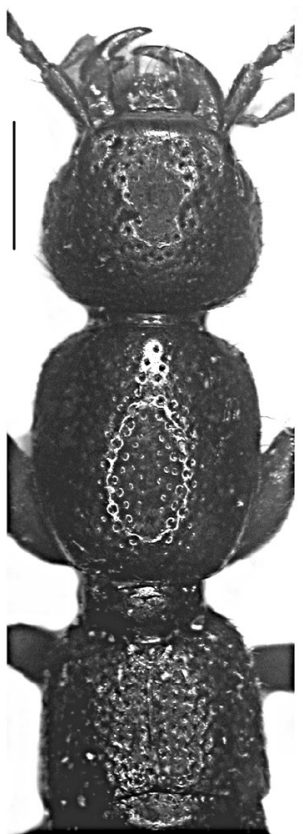

98

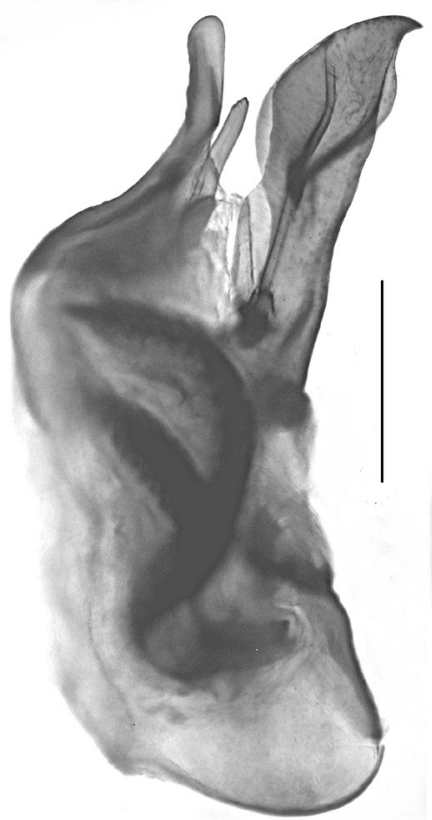

101

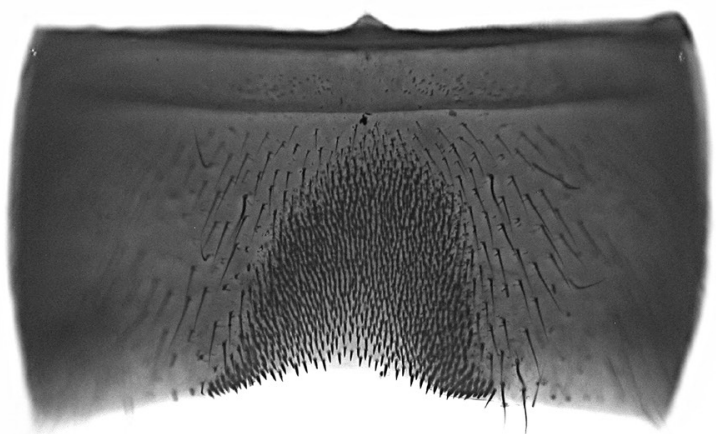

99

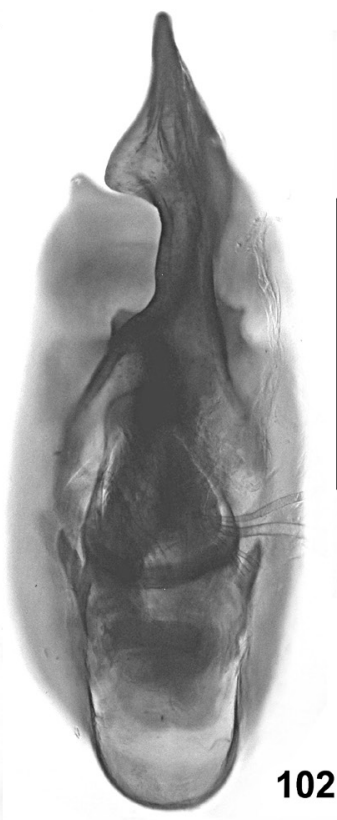

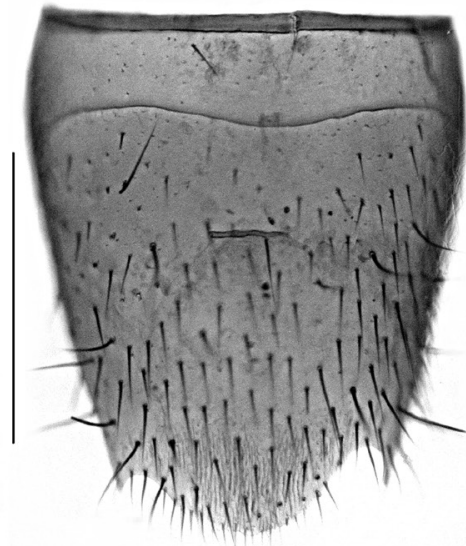

97 $\mathrm{o}^{\star}$ : protarsomeres I-IV strongly dilated; tergite VIII with weakly convex posterior margin; sternites III-VI unmodified; sternite VII (Fig. 99) strongly transverse, median impression extensive, of triangular shape, and with numerous strongly modified, very short black setae, posterior margin broadly concave; sternite VIII (Fig. 100) distinctly transverse, weakly asymmetric, with extensive, pronounced, and weakly asymmetric median impression, this impression with numerous strongly modified, very short black setae, posterior excision rather shallow, slightly asymmetric, and distinctly bisinuate; aedeagus (Figs 101-102) $2.0 \mathrm{~mm}$ long, strongly asymmetric, and of highly distinctive morphology; ventral process asymmetric and stout, subapically curved, and apically acute in lateral view; dorsal plate with apical portion strongly sclerotized, asymmetric, apically with a long right and a short left process, basal portion thin, lamellate, weakly sclerotized, and approximately as long as apical portion; internal sac with sclerotized apical structure, a large dark and sickle-shaped basal structure and with smaller membranous basal structure. 
q : unknown.

\section{Comparative notes:}

Lathrobium cornigerum is readily distinguished from all geographically close congeners by its external characters alone, especially its large size, the strongly transverse head, and the weakly oblong pronotum. In addition, it is characterized by the distinctive male sexual characters. Apart from the conspicuously short and dense short setae of the male sternite VIII, which are present also in L.fortepunctatum, possible synapomorphies linking L. cornigerum to other species recorded from China were not found.
Distribution and natural history:

The species is most likely endemic to the Wuyi Shan. The holotype was collected in the Huanggang Shan in Jiangxi province at an altitude of 1800-2050 m, together with Lathrobium depravatum and L. wuyicum.

\section{Lathrobium wuyicum sp. n.}

(Figs 103-111)

Type material:

Holotype ơ: "CHINA: JIANGXI prov., Wuyi Shan Nat. Res., Huangganshan [sic], (1800-2050 m), 5.vi.2001,

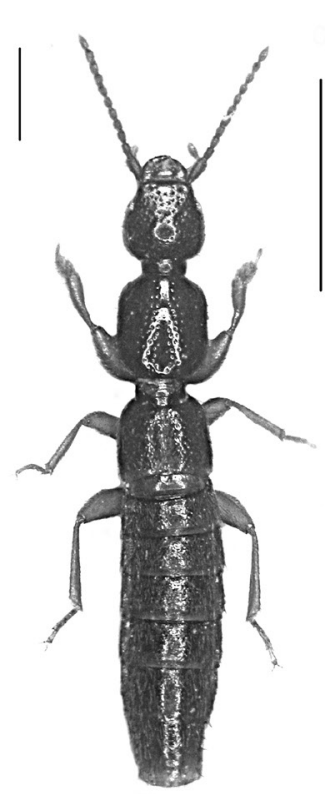

103

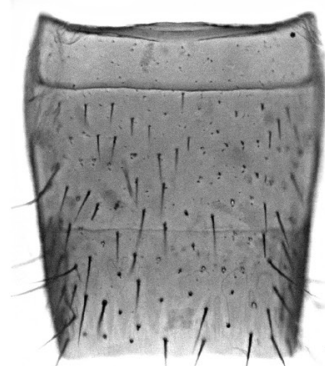

112

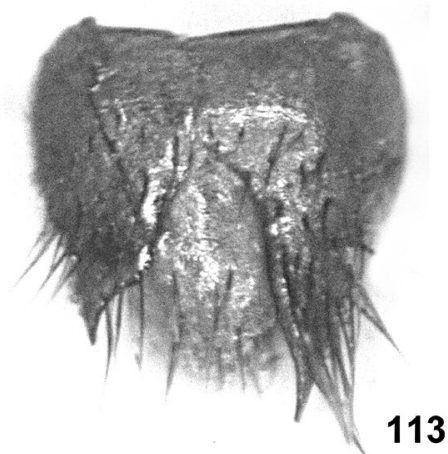

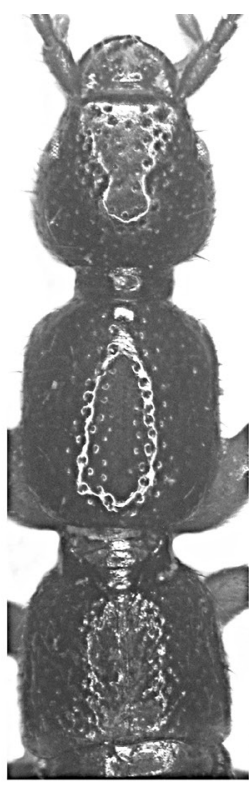

104

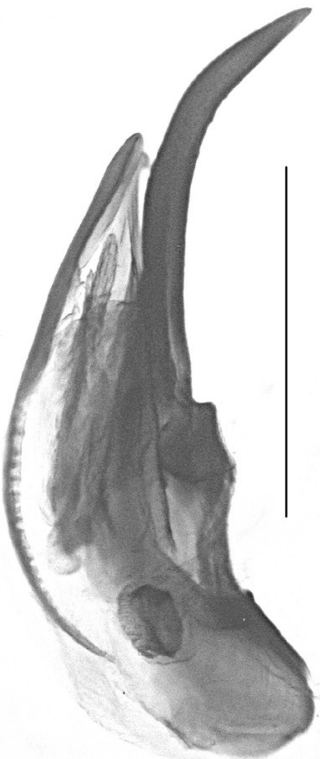

107

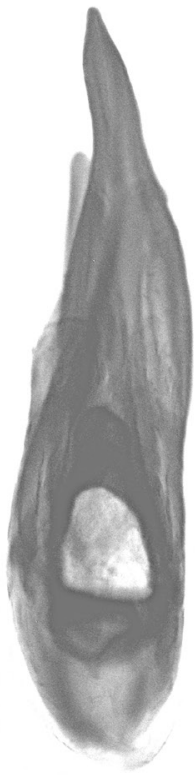

108

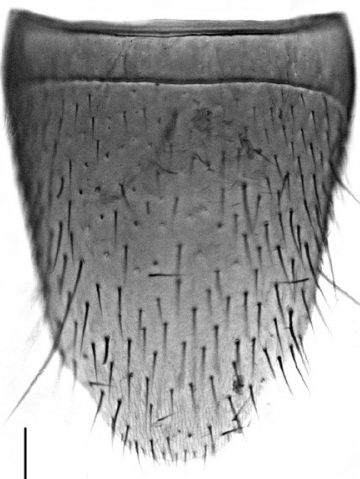

110

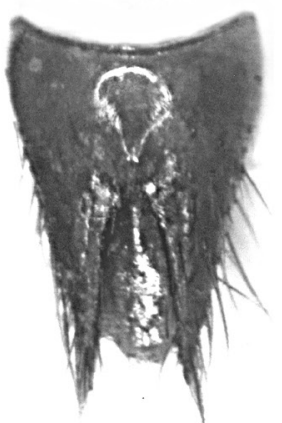

111

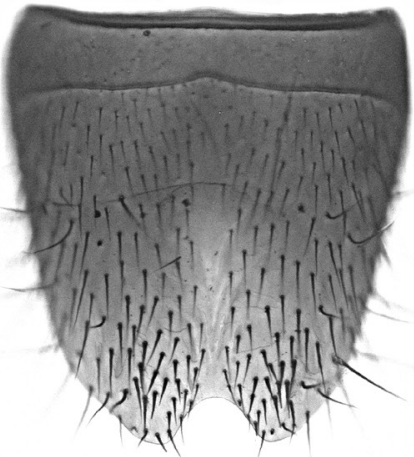

106

Figs 103-113: Lathrobium wuyicum sp. n. (103-111) and L. depravatum sp. n. (112-113): habitus (103); forebody (104); male sternite VII (105); male sternite VIII (106); aedeagus in lateral and in ventral view (107-108); female tergite VIII (109, 112); female sternite VIII (110); female tergites IX-X $(111,113)$. Scale bars: 103-104: $1.0 \mathrm{~mm}$; 105-113: $0.5 \mathrm{~mm}$. 
Hlaváč \& Cooter lgt / Holotypus ơ Lathrobium wuyicum sp. n., det. V. Assing 2012" (cAss). Paratypes: $30^{\star \top} \sigma^{\star}, 4$ ㅇ 우 same data as holotype (cAss).

\section{Etymology:}

The specific epithet (adjective) is derived from the name of the mountain range where this species is probably endemic.

\section{Description:}

Species of broad and somewhat depressed habitus and of intermediate size, with weakly pronounced sexual size dimorphism; body length 6.3-7.3 mm ( $\left.\sigma^{*}\right), 5.8-6.5 \mathrm{~mm}$ ( 9 ); length of forebody $3.1-3.3 \mathrm{~mm}\left(\mathrm{o}^{*}\right), 2.9-3.2 \mathrm{~mm}$ ( 9 ). Habitus as in Fig. 103. Coloration: body brown to dark-brown, posterior margin of elytra and often also suture more or less distinctly reddish; legs and antennae reddish.

Head (Fig. 104) weakly transverse, approximately 1.05 times as broad as long; punctation coarse and rather sparse, even sparser in median dorsal portion; interstices with shallow fine microreticulation. Eyes moderately small, approximately 0.4 times as long as postocular region in dorsal view and composed of slightly more than 50 ommatidia. Antenna 1.6-1.7 mm long.

Pronotum (Fig. 104) broad, approximately 1.17 times as long as broad and 1.1 times as broad as head; punctation similar to that of head; impunctate midline rather broad; interstices without microsculpture.

Elytra (Fig. 104) short, approximately 0.52 times as long as pronotum; punctation shallow and weakly defined. Hind wings completely reduced. Protarsus with pronounced sexual dimorphism.

Abdominal tergites III-VI with fine and dense, tergite VII with distinctly sparser punctation; interstices with shallow microsculpture and somewhat glossy; posterior margin of tergite VII without palisade fringe; tergite VIII with moderately pronounced sexual dimorphism.

$0^{*}$ : protarsomeres I-IV strongly dilated; tergite VIII with weakly convex posterior margin; sternites III-VI unmodified; sternite VII (Fig. 105) strongly transverse, with small and shallow median impression posteriorly, this impression with sparse and moderately modified short black setae; sternite VIII (Fig. 106) as long as broad, gradually tapering posteriad, and symmetric, with shallow median impression, middle of sternite narrowly without setae, posterior portion of sternite with weakly modified setae not forming defined clusters, pos- terior excision moderately deep and broadly U-shaped; aedeagus (Figs 107-108) approximately $1.1 \mathrm{~mm}$ long and nearly symmetric; ventral process very slender and apically acute, subapically curved in lateral view; dorsal plate lamellate and smoothly curved in lateral view, basal portion very long, approximately as long as apical portion; internal sac with sclerotized apical spine.

i : protarsomeres I-IV distinctly less dilated than in male; posterior margin of tergite VIII obtusely pointed in the middle (Fig. 109); sternite VIII (Fig. 110) approximately $1.0 \mathrm{~mm}$ long and distinctly oblong, posterior margin convexly produced in the middle; tergite IX with moderately long and undivided median portion, and with moderately long and slender postero-lateral processes; tergite X nearly flat, slightly longer than median portion of tergite IX (Fig. 111).

\section{Comparative notes:}

Although similar in the broad and somewhat depressed habitus to other species distributed in the Wuyi Shan, except L. depravatum, closer phylogentic affiliations are not suggested by the completely different male and female sexual characters. Apart from the sexual characters, L. wuyicum is readily distinguished from other geographically close congeners with a broad and depressed body by its smaller body size.

\section{Distribution and natural history:}

The species is most likely endemic to the Wuyi Shan. The specimens were collected in the Huanggang Shan in Jiangxi province at an altitude of 1800-2050 m, together with Lathrobium depravatum and $L$. cornigerum.

\section{Lathrobium sp.}

\section{Material examined:}

1 : "CHINA: JIANGXI prov., Wuyi Shan Nat. Res., Huangganshan [sic], (1800-2050 m), 5.vi.2001, Hlaváč \& Cooter lgt." (cAss).

\section{Comment:}

Except for the slightly larger body size, the above female is externally similar to L. daicongchaoi. There is little doubt that it represents an undescribed species. 


\section{Species from Guizhou}

Only one Lathrobium species was previously known from Guizhou, L. guizhouense CHEN et al., 2005 from the Fajing Shan in the northeast of the province.

\section{Lathrobium pium sp. $\mathrm{n}$.}

(Figs 114-121)

\section{Type material:}

Holotype ơ: "CHINA: Guizhou, Leishan Co., SE Kaili, NE Leishan, Leigong Shan, E-slope, $26^{\circ} 22.56^{\prime} \mathrm{N}, 108^{\circ} 13.40^{\prime} \mathrm{E} /$ ca. $300 \mathrm{~m} \mathrm{~S}$ of pass, 14./16.6.2001, ca. $1700 \mathrm{~m}$, leg. Schillhammer (5) / Holotypus ơ Lathrobium pium sp. n., det. V. Assing 2013" (NHMW). Paratypes: 1 o 1 , 1 : same data as holotype (NHMW, cAss).

\section{Etymology:}

The specific epithet (Latin, adjective: pious) alludes to the shape of the aedeagus, which, in lateral view, somewhat reminds of a praying person.

\section{Description:}

Relatively large species; body length 9.0-10.0 mm; length of forebody 4.5-4.7 mm. Habitus as in Fig. 114. Coloration: body blackish-brown to black; legs reddish-brown to dark-brown with paler tarsi; antennae dark-reddish.

Head (Fig. 115) approximately as broad as long or weakly transverse; punctation moderately coarse, rather dense in lateral and posterior portion and sparse in median and anterior dorsal portion; interstices with fine and distinct microreticulation. Eyes moderately small, approximately 0.3 times as long as postocular region in dorsal view and with $>50$ ommatidia. Antenna approximately $2.5 \mathrm{~mm}$ long.

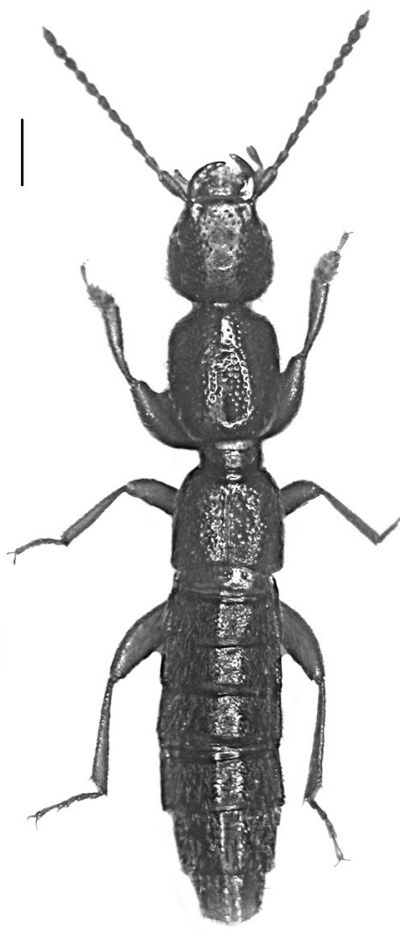

114

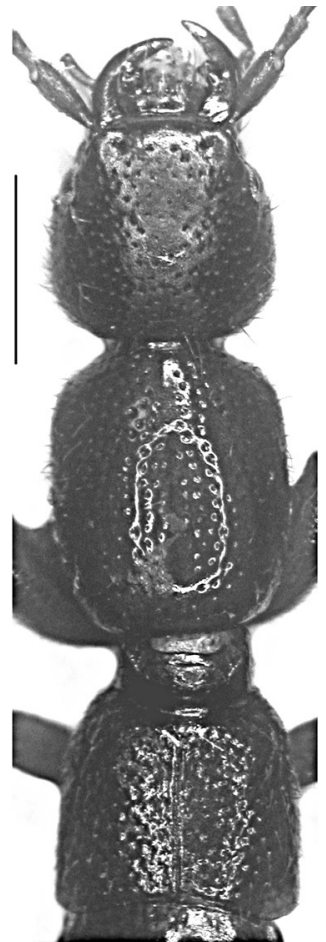

115

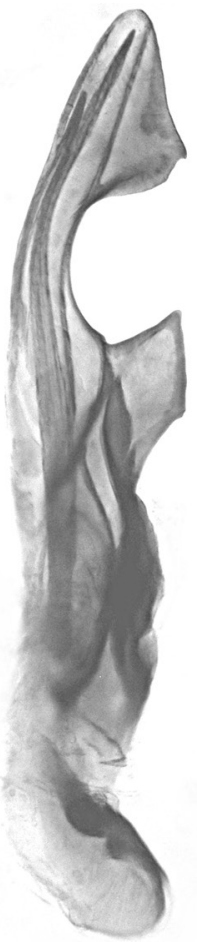

118
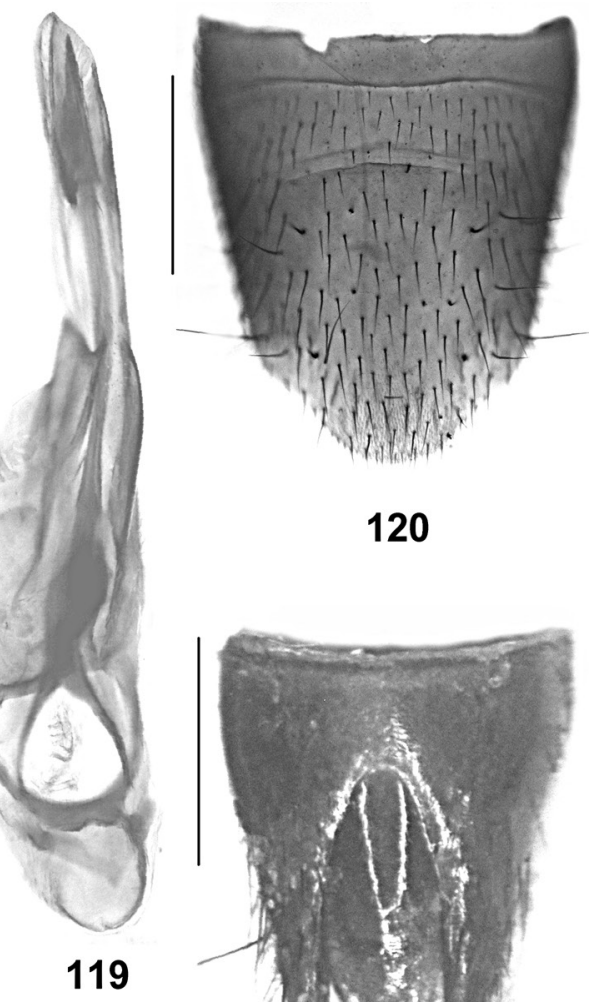

120

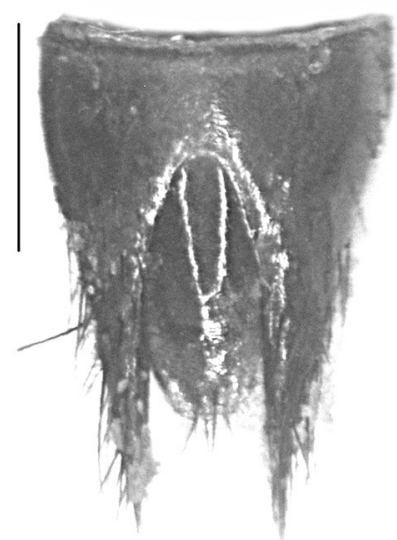

121

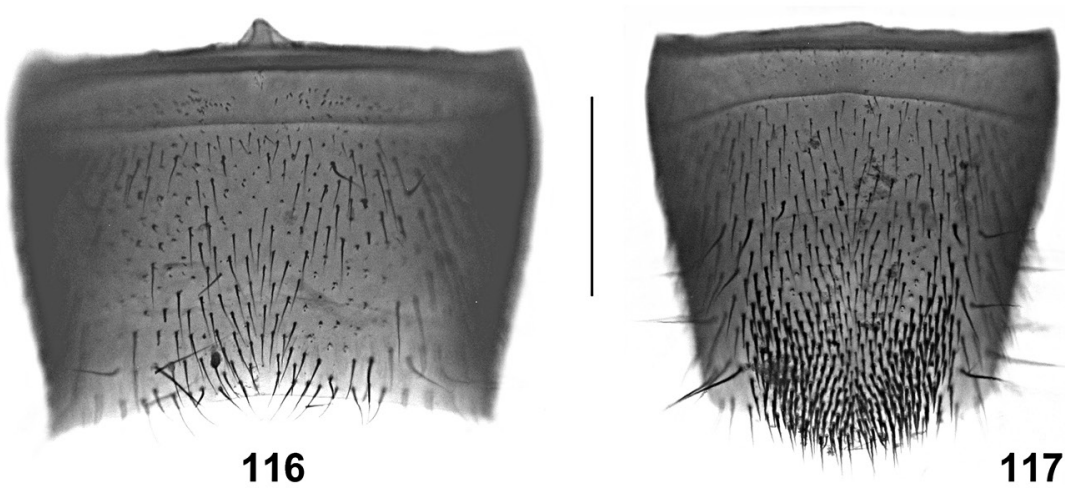

Figs 114-121: Lathrobium pium sp. n.: habitus (114); forebody (115); male sternite VII (116); male sternite VIII (117); aedeagus in lateral and in ventral view (118-119); female sternite VIII (120); female tergites IX-X (121). Scale bars: 114-115: 1.0 mm; 116-121: $0.5 \mathrm{~mm}$ 
Pronotum (Fig. 115) approximately 1.2 times as long as broad and about 1.05 times as broad as head; punctation somewhat coarser than that of head and moderately dense; impunctate midline rather narrow; interstices without microsculpture.

Elytra (Fig. 115) approximately 0.52 times as long as pronotum, not particularly broad; punctation shallow and moderately dense. Hind wings completely reduced. Protarsomeres with moderately pronounced sexual dimorphism.

Abdomen slightly broader than elytra; punctation of tergites III-VI moderately dense, that of tergites VII-VIII somewhat sparser; interstices with shallow, but distinct microsculpture; posterior margin of tergite VII without palisade fringe; tergite VIII without sexual dimorphism, posterior margin distinctly convex in both sexes.

$\sigma^{*}$ : protarsomeres I-IV strongly dilated; sternite VII (Fig. 116) moderately transverse, with sparse and very weakly modified black setae in posterior median portion; sternite VIII (Fig. 117) approximately as long as broad, with extensive cluster of dense, moderately modified black setae, and with distinctly convex posterior margin, posterior excision absent; aedeagus (Figs 118-119) approximately $1.6 \mathrm{~mm}$ long, slender, distinctly asymmetric, and with small basal portion; ventral process of highly distinctive shape, asymmetric, with sharp and, in lateral view, strongly excavated ventral margin; dorsal plate indistinct, weakly sclerotized; internal sac with very long, basally dilated, and apically bifid sclerotized spine.

\%: protarsomeres I-IV distinctly dilated, but somewhat less so than in male; sternite VIII (Fig. 120) approximately $1.2 \mathrm{~mm}$ long, weakly oblong, and posteriorly convexly produced; tergite IX with short antero-median portion without median suture, and with moderately long postero-lateral processes; tergite $\mathrm{X}$ weakly convex in cross-section, slightly more than twice as long as anteromedian portion of tergite IX (Fig. 121).

\section{Comparative notes:}

The similar morphology of the aedeagus (ventral process slender and distinctly asymmetric, small basal portion, presence of a long spine in internal sac) and of the female terminalia (short antero-median portion of tergite IX), L. pium belongs to the L. fissispinosum group (see AssING in press). It is distinguished from L. guizhouense from the Fanjing Shan, previously the sole representative of the genus recorded from Guizhou, by larger body size, the different shape and chaetotaxy of the male sternite VIII, and by the distinctive morphology of the aedeagus. For illustrations of the habitus, the male sternite VIII, and the aedeagus of L. guizhouense see CHEN et al. (2005).
Distribution and natural history:

Lathrobium pium is probably endemic to the Leigong Shan, southeastern Guizhou, where the specimens were collected at an altitude of approximately $1700 \mathrm{~m}$.

\section{Lathrobium sp.}

\section{Material examined:}

1 9 : "CHINA: Guizhou, Leishan Co., SE Kaili, NE Leishan, Leigong Shan, E-slope, $26^{\circ} 23.39^{\prime} \mathrm{N}, 108^{\circ} 13.33^{\prime} \mathrm{E} /$ $2.5 \mathrm{~km}$ E of pass, 23./24.6.2001, ca. $1600 \mathrm{~m}$, leg. Schillhammer (17 A)" (NHMW).

\section{Comment:}

The above female undoubtedly represents an undescribed species. It was collected close to the type locality of L. pium, from which it is distinguished by distinctly smaller size (body length $6.5 \mathrm{~mm}$; length of forebody $3.5 \mathrm{~mm}$ ), paler coloration, and by the female secondary sexual characters.

\section{Acknowledgements}

I am indebted to the colleagues indicated in the material section for the loan of material under their care, particularly to Michael Schülke, Aleš Smetana, and Andreas Pütz for the generous gift of several single males (holotypes), as well as to Peter Hlaváč (Praha) for the gift of his Lathrobium material from Fujian and Jiangxi. In addition, I am grateful to Zhong Peng (Shanghai) for providing additional data for L. bibaculatum and to Benedikt Feldmann (Münster) for proof-reading the manuscript.

\section{References}

Assing, V.2012a: Unterfamilie Paederinae Fleming, 1821; pp. 322-369, 380-383. - In: Assing, V. \& SCHÜLKE, M. (eds): Freude-Harde-Lohse-Klausnitzer. - Die Käfer Mitteleuropas. Band 4. Staphylinidae I. Zweite neubearbeitete Auflage. - Spektrum Akademischer Verlag, Heidelberg and Berlin: I-XII, 1-560.

Assing, V. 2012b: A revision of East Palaearctic Lobrathium (Coleoptera: Staphylinidae: Paederinae). - Bonn Zoological Bulletin 61 (1): 49-128.

Assing, V. in press: On the Lathrobium fauna of China I. The species of the Qinling Shan, the Daba Shan, and adjacent mountain ranges (Coleoptera: Staphylinidae: Paederinae). - Bonn Zoological Bulletin 62 (1) (2013). Assing, V.; Peng, Z. \& Zhao, M.-J. 2013: On the Lathrobium fauna of the Emei Shan, Sichuan, China (Coleoptera, Staphylinidae, Paederinae). - ZooKeys 277: 47-67. 
Chen, J.; LI, L.-Z. \& Zhao, M.-J. 2005: A new species of the genus Lathrobium (Coleoptera, Staphylinidae) from Guizhou Province, Southwest China. - Acta Zootaxonomica Sinica 30 (3): 598-600.

Peng, Z.; Li, L.-Z. \& ZhaO, M.-J. 2012a: Taxonomic study on Lathrobium Gravenhorst (Coleoptera, Staphylinidae, Paederinae) from Longwangshan Mountain, East China. - ZooKeys 165: 21-32.

Peng, Z.; LI, L.-Z. \& ZhaO, M.-J. 2012b: Three new species of Lathrobium Gravenhorst (Coleoptera: Staphylinidae: Paederinae) from Sichuan, Southwest China. - ZooKeys 205: 33-44.

Peng, Z.; LI, L.-Z. \& ZhaO, M.-J. 2012c: Two new apterous species of Lathrobium Gravenhorst (Coleoptera, Staphylinidae, Paederinae) from Fujian, East China. - ZooKeys 218: 57-63.

Peng, Z.; LI, L.-Z. \& ZhaO, M.-J. 2012d: Three new species of the genus Lathrobium GravenHorst (Coleoptera, Staphylinidae, Paederinae) from the Jiulongshan Natural Reserve, East China. - ZooKeys 184: 57-66.
Peng, Z.; LI, L.-Z. \& Zhao, M.-J. 2012e: Five new apterous species of the genus Lathrobium Gravenhorst (Coleoptera: Staphylinidae: Paederinae) from the Baishanzu Natural Reserve, East China. - ZooKeys 251: 69-81.

WATANABE, Y. 1999a: Two new subterranean staphylinids (Coleoptera) from East China. - Elytra, Tokyo 27 (1): 249-257.

Watanabe, Y. 1999b: Two new species of the group of Lathrobium pollens/brachypterum (Coleoptera, Staphylinidae) from Zhejiang Province, East China. Elytra, Tokyo 27 (2): 573-580. 